DOI: $10.2478 / \mathrm{v} \cdot 10169-012-0019-7$

\title{
NUMERICAL MESOSCOPIC ANALYSIS OF FRACTURE IN FINE-GRAINED CONCRETE
}

\author{
Ł. SKARŻYŃSKI ${ }^{1}$, J. TEJCHMAN ${ }^{2}$
}

\begin{abstract}
This paper presents numerical two-dimensional results for fine-grained concrete under quasi-static three-point bending at meso-scale. Concrete was modelled as a random heterogeneous three-phase material. The simulations for notched concrete beams were carried out with the standard finite element method using an isotropic damage constitutive model enhanced by a characteristic length of micro-structure by means of a non-local theory. The effect of the volume fraction, shape, size, statistical distribution and stiffness of aggregate was analysed. Moreover, the effect of the bond thickness, notch size and characteristic length of micro-structure on the material behaviour was numerically investigated. The FE results were compared with own laboratory test results and other meso-scale calculations for three-phase concrete elements.
\end{abstract}

Key words: aggregate, concrete, finite element analysis, interfacial transition zone, microstructure.

\section{INTRODUCTION}

Fracture process is a fundamental phenomenon in concrete materials under mechanical loading (Bažant and Planas [1], Lilliu and van Mier [2]). It is a major reason of damage in concrete contributing to a significant degradation of the material strength. Cracks are always preceded by the formation of narrow zones of intense deformation (micro-cracking zones) which act as a precursor to ultimate fracture and failure. The width of localized zones is commonly not negligible to cross-section dimensions of a concrete specimen and is large enough to cause significant energy release and accompanying stress redistribution in the structure (BažAnt and Planas [1]). Hence, an understanding of the mechanism of the formation of localized zones (width and spacing) is crucial to evaluate mobilized material strength close to the peak and in the post-peak regime and related size effect, and thus to ensure safety to the civil engineering structures. The mechanism of strain localization strongly depends upon a heterogeneous structure of materials over many different scales, changing e.g. in

\footnotetext{
${ }^{1}$ Faculty of Civil and Environmental Engineering, Gdańsk University of Technology, ul. G. Narutowicza 11/12, 80-233 Gdańsk, Poland, e-mail: 1skarzyn@pg.gda.pl

${ }^{2}$ Faculty of Civil and Environmental Engineering, Gdańsk University of Technology, ul. G. Narutowicza 11/12, 80-233 Gdańsk, Poland, email: tejchmk@pg.gda.pl
} 
concrete from the few nanometers (hydrated cement) to the millimetres (aggregate particles). Therefore, to take strain localization into account, material composition (micro-structure) has to be taken into account (Bažant and Planas [1], LiLliu and van Mier [2], Nielsen et al. [3], Sengul et al. [4], Kozicki and Tejchman [5], He [6]). At the meso-scale, concrete can be considered as a composite material by distinguishing 3 important phases: cement matrix, aggregate and interfacial transition zones ITZs. In particular, the presence of aggregate and ITZs is important since the volume fraction of aggregate can be as high as 70-75\% in concrete and ITZs are always the weakest regions in concrete. The concrete behaviour at the meso-scale fully determines the macroscopic non-linear behaviour. The advantage of meso-scale modelling is the fact that it directly simulates micro-structure and can be used to comprehensively study local phenomena at the micro-level such as the mechanism of the initiation, growth and formation of localized zones and cracks (He [6], Kiм and Aвu Al-Rub [7], SнанBEYK et al. [8]). Through that the mesoscopic results allow for a better calibration of continuum models enhanced by micro-structure and an optimization design of concrete with enhanced strength and ductility. The disadvantages are: very high computational cost, inability to model aggregate shape accurately and the difficulty to experimentally measure the properties of ITZs. The concrete behaviour at the meso-scale can be described with continuum and discrete models. In this study we used an enhanced continuum approach. The intention of our 2D meso-mechanical continuum calculations is to investigate the effect of different parameters on the fracture behaviour of a fine-grained notched concrete beam under tensile loading during quasi-static three-point bending. Concrete was modelled as a random heterogeneous three-phase material. To obtain mesh-objective FE results for concrete specimens with localized zones, a simple isotropic continuum constitutive damage model (Marzec et al. [9], SKARŻYŃsKi and Tejchman [10]) enhanced by a characteristic length of micro-structure by means of a non-local theory (PiJauder-CABot and Bažant [11], BažAnt and Jirasek [12], Boвiśski et al. [13]) was used. The effect of meso-structural features such as volume fraction, shape, size, statistical distribution, grading curve and stiffness of aggregate was carefully analysed. In addition, the effect of the thickness of the bond between cement matrix and aggregate, notch size in the beam and characteristic length of micro-structure on the fracture behaviour was numerically investigated. The results of our mesoscopic analyses were directly compared with corresponding laboratory test results with notched concrete beams, where the width, length and shape of a localized zone on the surface of notched concrete beams was determined with a Digital Image Correlation (DIC) technique (SKARŻYŃsKi et al. [14]). In addition, our FE results were also compared with recent meso-scale continuum computations performed by GiTMAN et al. [15], Du and Sun [16], He et al. [17], He [6], Кім and Abu Al-Rub [7] for three-phase concrete elements under uniaxial tension. In the calculations by GITMAN et al. [15], HE et al. [17] and HE [6], the same constitutive model was used as in our study. In turn, Кім and AвU Al-Ruв [7] applied a coupled plasticity-damage model without enhancements. 
The paper is a continuation of our earlier initial meso-scale calculations (SKARŻYŃSKI and Tejchman [10]) where the main attention was paid to a direct comparison between numerical results and experimental ones in 3 geometrically similar notched beams under quasi-static bending of very fine and fine-grained concrete with respect to load-displacement curves, width and shape of a localized zone and a related size effect. The present analysis is more comprehensive at the meso-level and concerns the smallest notched concrete beam only.

\section{Constitutive MOdel For CONCRETE}

A simple isotropic damage continuum model was used for describing the material degradation with the aid of a single scalar damage parameter $D$, growing monotonically from zero (undamaged material) to one (completely damaged material) (Katchanov [18], Simo and JU [19]). The relationship between the stress $\sigma_{i j}$ and strain tensor $\varepsilon_{k l}$ is

$$
\sigma_{i j}=(1-D) C_{i j k l}^{e} \varepsilon_{k l},
$$

where $D$ denotes the scalar damage parameter growing monotonically from zero (undamaged material) to one (completely damaged material) and $C_{i j k l}^{e}$ is the linear elastic material stiffness matrix. The loading function of damage is as follows

$$
f(\tilde{\varepsilon}, \kappa)=\tilde{\varepsilon}-\max \left\{\kappa, \kappa_{0}\right\},
$$

where $\kappa_{0}$ denotes the initial value of $\kappa$ when damage begins. If the loading function $f$ is negative, damage does not develop. During monotonic loading, the parameter $\kappa$ grows (it coincides with $\tilde{\varepsilon}$ ) and during unloading and reloading it remains constant. A Rankine failure type criterion was assumed to define the equivalent strain measure $\tilde{\varepsilon}$ (JiRASEK and Marfia [20])

$$
\tilde{\varepsilon}=\frac{\max \left\{\sigma_{i}^{e f f}\right\}}{E},
$$

where $E$ denotes the modulus of elasticity and $\sigma_{i}^{e f f}$ are the principal values of the effective stress tensor

$$
\sigma_{i j}^{e f f}=C_{i j k l}^{e} \varepsilon_{k l} .
$$

If all principal stresses are negative, the loading function $f$ is negative and no damage takes place.

To describe the evolution of the damage parameter $D$ determining the shape of a softening curve during tensile loading, the exponential law was used (Peerlings et al. [21])

$$
D=1-\frac{\kappa_{0}}{\kappa}\left(1-\alpha+\alpha e^{-\beta\left(\kappa-\kappa_{0}\right)}\right),
$$


where $\alpha$ and $\beta$ are the material constants. The constitutive isotropic damage model for concrete requires 5 material constants only (2 elastic and 3 plastic): $E, v, \kappa_{0}, \alpha$ and $\beta$. The model is suitable for tensile failure (Marzec et al. [9], SkarżyŃski et al. [14]) and mixed tensile-shear failure (Bовiński and Teјсhman [22], Syroka et al. [23]) in quasi-brittle materials. Its disadvantages are that it cannot realistically describe irreversible deformations, volume changes and shear failure (Simone and Stuys [24]).

To capture strain localization in concrete, to obtain mesh-independent results and finally to include a characteristic length of micro-structure $l_{c}$ (which determines the width of a localized zone), an integral-type non-local theory was used in FE simulations as a regularization technique (BažAnT and JiRasek [12], Bobiński and Tejchman [25]). Alternatively, a a characteristic length of micro-structure could be also introduced by means of a second-gradient theory (e.g. Wosatko et al. [26]). The equivalent strain measure $\tilde{\varepsilon}$ was replaced by its non-local value $\bar{\varepsilon}$ (PIJAuder-CABot and BAŽANT [11]) to evaluate the loading function (Eq.2) and to calculate the damage threshold parameter $\kappa$

$$
\bar{\varepsilon}=\frac{\int_{V} \omega(\|x-\xi\|) \tilde{\varepsilon}(\xi) d \xi}{\int_{V} \omega(\|x-\xi\|) d \xi},
$$

where $V$ - the body volume, $x$ - the coordinates of the considered (actual) point, $\xi-$ the coordinates of surrounding points and $\omega$ - the weighting function. As a weighting function $\omega$, the Gauss distribution function was used

$$
\omega(r)=\frac{1}{l_{c} \sqrt{\pi}} e^{-\left(\frac{r}{l_{c}}\right)^{2}},
$$

where the parameter $r$ is a distance between two material points. The averaging in Eq.7 is restricted to a small representative area around each material point (the influence of points at the distance of $r=3 \times l_{c}$ is only $0.01 \%$ ). To obtain fully mesh-objective $\mathrm{FE}$ results, the maximum size of finite elements should be equal to $(2-3) \times l_{c}$ (BoBINSKI and Tejchman [25]) A characteristic length is usually related to material micro-structure and is determined with an inverse identification process of experimental data (LE BELLĚGO et al. [27], SKARŻý́ski et al. [14]). The FE calculations were carried out using a large-displacement analysis. The non-local averaging was performed in the current configuration. A non-local approach was applied during softening.

Due to the fact that the measured width of a localized zone was not clearly dependent upon the concrete mix (SKARŻYŃsKi et al. [14]), in the first step the mesoscopic characteristic length $l_{c}^{m}$ was simply imposed such that the numerical results agreed with the experimental observations $\left(l_{c}^{m}=1.5 \mathrm{~mm}\right)$. In our future numerical investigations, it will be related to concrete microstructure (aggregate size or aggregate spacing). 


\section{INPUT DATA FOR MESOSCOPIC FE CALCULATIONS}

The simplified two-dimensional mesoscopic FE simulations were performed with a small-size notched free-supported beam made from fine-grained concrete $(80 \times 320 \times 40$ $\mathrm{mm}^{3}$ ) subjected to quasi-static three-point bending (Fig. 1). The same concrete beam was experimentally investigated by Le BelLĚGo et al. [27]) and by SKARŻYŃSKI et al. [14] in size effect tests. The beam was subjected to a vertical displacement at the top mid-point at a very slow rate. Concrete at the meso-scale was considered as a three-phase material encompassing cement matrix, aggregate and interfacial transition zones (ITZs) between cement matrix and aggregate. Four different fine-grained concrete mixes were numerically analysed with the mean aggregate diameter $d_{50}=2 \mathrm{~mm}, d_{50}=4$ $\mathrm{mm}, d_{50}=4 \mathrm{~mm}$ and $d_{50}=0.5 \mathrm{~mm}$, respectively (Fig. 2). To reduce the calculation time, the size of the smallest inclusions had to be limited (Fig. 2). Thus, the final aggregate size varied between the minimum value $d_{\min }=2 \mathrm{~mm}$ and maximum value $d_{\max }=8 \mathrm{~mm}$ (aggregate size distribution curve ' $a$ ' of Fig. 2), $d_{\min }=2 \mathrm{~mm}$ and $d_{\max }=10$ $\mathrm{mm}$ (aggregate size distribution curve ' $b$ ' of Fig. 2), $d_{\min }=2 \mathrm{~mm}$ and $d_{\max }=6 \mathrm{~mm}$ (aggregate size distribution curve ' $c$ ' of Fig. 2) and $d_{\min }=0.5 \mathrm{~mm}$ and $d_{\max }=3 \mathrm{~mm}$ (aggregate size distribution curve ' $d$ ' of Fig. 2). The aggregate was generated according to the method given by ECKARDT and KöNKE [28]. The aggregate was randomly placed starting with the largest ones and preserving a certain mutual distance (vAN MIER et al. [29])

$$
D_{p}>1.1 \frac{D_{1}+D_{2}}{2}
$$

where $D_{p}$ is the distance between two neighbouring particle centres and $D_{1}, D_{2}$ are the diameters of two particles, respectively. The aggregate volume fraction was $\rho=30 \%$, $\rho=45 \%$ or $\rho=60 \%$.

The calculations were carried out with one set of the material constants $E, v, \kappa_{0}, \alpha, \beta$ and $l_{c}^{m}$ given in Tab. 1, which were prescribed to finite elements corresponding to a specified concrete phase. These material constants were determined with the aid of comparative FE analyses of both the load-deflection curves and width of a localized zone above the notch with corresponding laboratory experiments (LE BeLLĚGo et al. [28] and SKARŻYŃSKI et al. [14]) which were carried out with 3 geometrically similar notched beams using fine-grained concrete $\left(d_{\max }=8.0 \mathrm{~mm}, d_{50}=2.0 \mathrm{~mm}\right.$ corresponding to the curve ' $a$ ' of Fig. 2) and very fine-grained concrete $\left(d_{\max }=3.0 \mathrm{~mm}, d_{50}=0.5 \mathrm{~mm}\right.$ corresponding to the curve ' $d$ ' of Fig. 2) (Figs. 3 and 4) (Skarżyński and Tejchman [10]). The modulus of elasticity $E$ and crack initiation strain $\kappa_{0}$ were solely changed in 3 phases (the remaining constants were the same: $v=0.2, \alpha=0.95, \beta=200$ and $l_{c}=1.5$ $\mathrm{mm})$. In turn, the macroscopic calculations for a homogeneous concrete material were carried out with the following material constants: $E=38.5 \mathrm{GPa}, v=0.2, \kappa_{0}=1.3 \times 10^{-4}$, $\alpha=0.95, \beta=400$ and $l_{c}=2 \mathrm{~mm}$ (SKarżyŃSKi and Tejchman [10]). In general, the material constants should be determined with laboratory tensile tests for each phase 


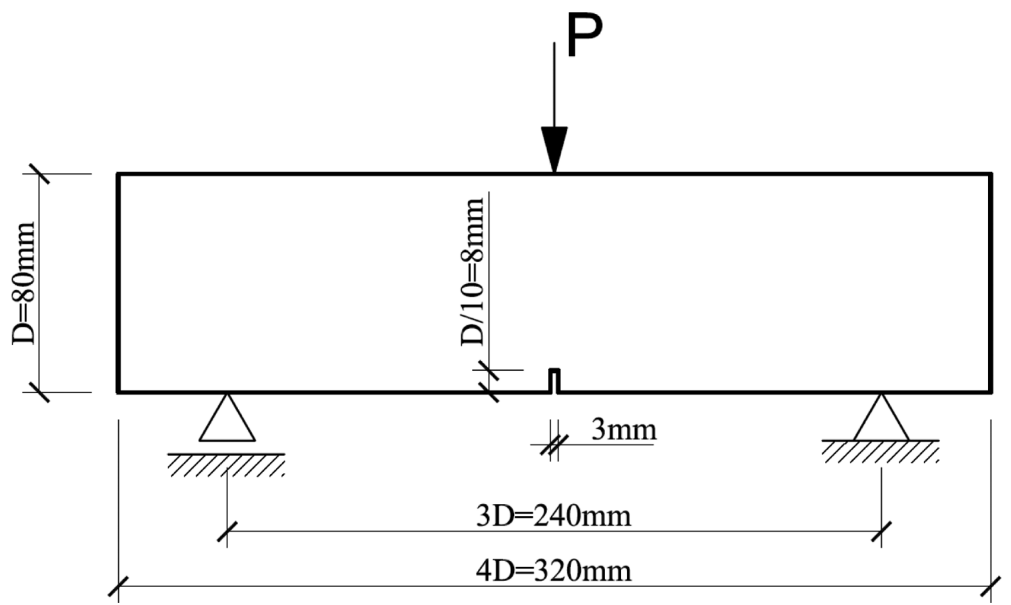

Fig. 1. Geometry of small-size notched concrete beam with thickness of $40 \mathrm{~mm}$ subjected to quasi-static three-point bending used in tests by Le Bellěgo et al. [26] and Skarżyński et al. [14] ( $P$ - vertical force, $D=80 \mathrm{~mm}-$ beam height).

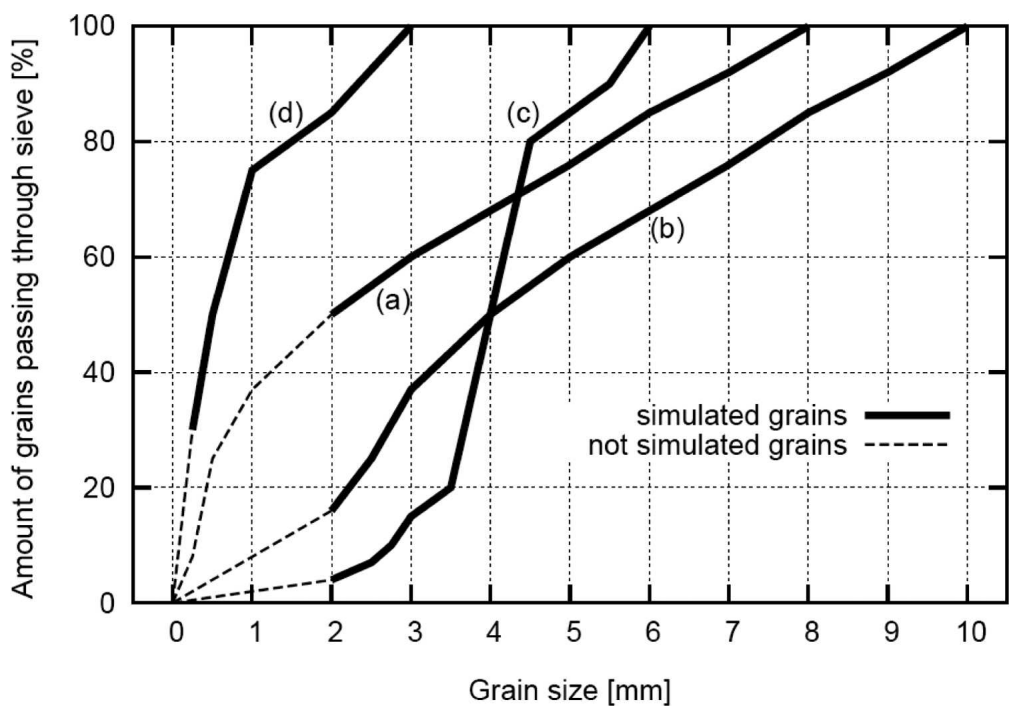

Fig. 2. Aggregate size distribution curves assumed for FE calculations (note that small aggregates were cut off to reduce the computation time). 
(that is certainly possible for aggregate and cement matrix but not feasible for ITZs). Since the material constants for aggregate and cement matrix were not separately determined with laboratory experiments, other relationships between material constants $E$ and $\kappa_{0}$ were also possible to obtain a satisfactory agreement between experiments and $\mathrm{FE}$ analyses.

Table 1

Material parameters assumed for FE calculations of concrete notched beams under bending at meso-scale (Skarżyński and Tejchman [10]).

\begin{tabular}{|c|c|c|c|}
\hline Parameters & Aggregate & Cement matrix & ITZ \\
\hline Modulus of elasticity $E[\mathrm{GPa}]$ & 40 & 35 & 30 \\
\hline Poisson's ratio $v[-]$ & 0.2 & 0.2 & 0.2 \\
\hline Crack initiation strain $\kappa_{0}[-]$ & - & $1 \times 10^{-4}$ & $7 \times 10^{-4}$ \\
\hline Residual stress level $\alpha[-]$ & - & 0.95 & 0.95 \\
\hline Slope of softening $\beta[-]$ & - & 200 & 200 \\
\hline Mesoscopic characteristic length $l_{c}^{m}[\mathrm{~mm}]$ & - & 1.5 & 1.5 \\
\hline
\end{tabular}

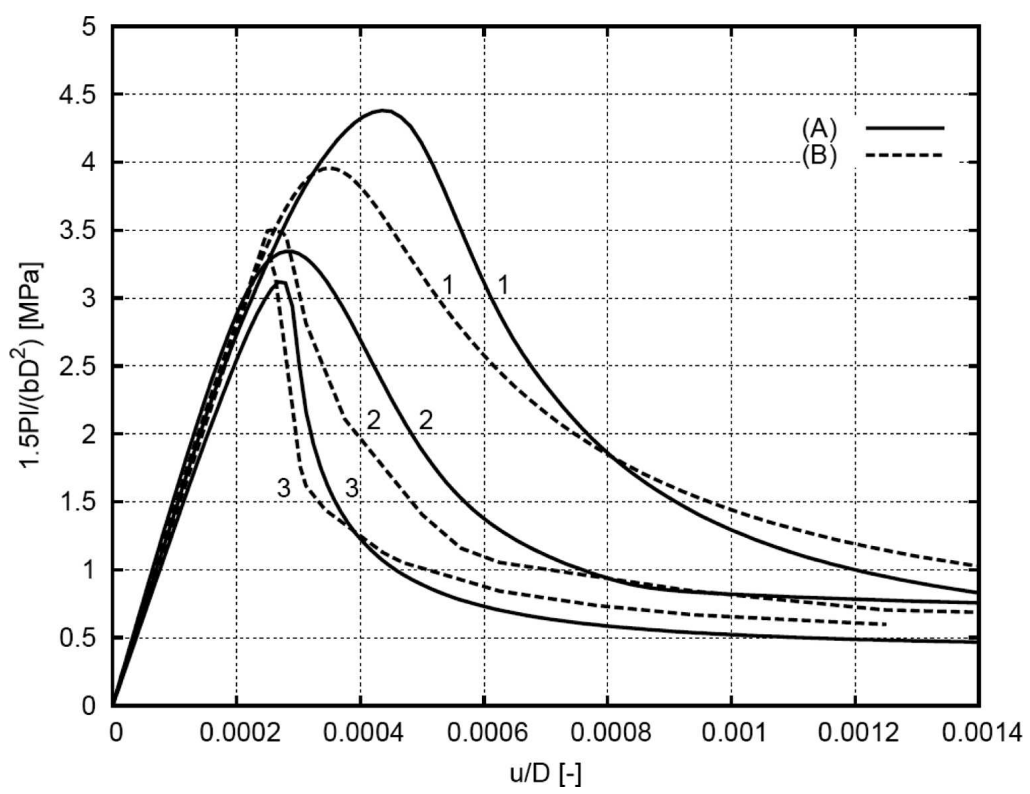

Fig. 3. Calculated nominal strength $1.5 P l /\left(b D^{2}\right)$ versus normalised beam deflection $u / D(P$ - vertical force, $u$ - beam deflection, $D$ - beam height, $b$ - beam width, $l$ - beam span): A) FE-results,

B) experiments by Le Bellěgo et al. [26]: 1) small-size beam $80 \times 320 \times 40 \mathrm{~mm}^{3}$, 2) medium-size beam $160 \times 640 \times 40 \mathrm{~mm}^{3}$, 3) large-size beam $320 \times 1280 \times 40 \mathrm{~mm}^{3}$ (three-phase random heterogeneous fine-grained concrete with characteristic length of micro-structure $l_{c}^{m}=1.5 \mathrm{~mm}$ ) (Skarżyński and Tejchman [14]). 

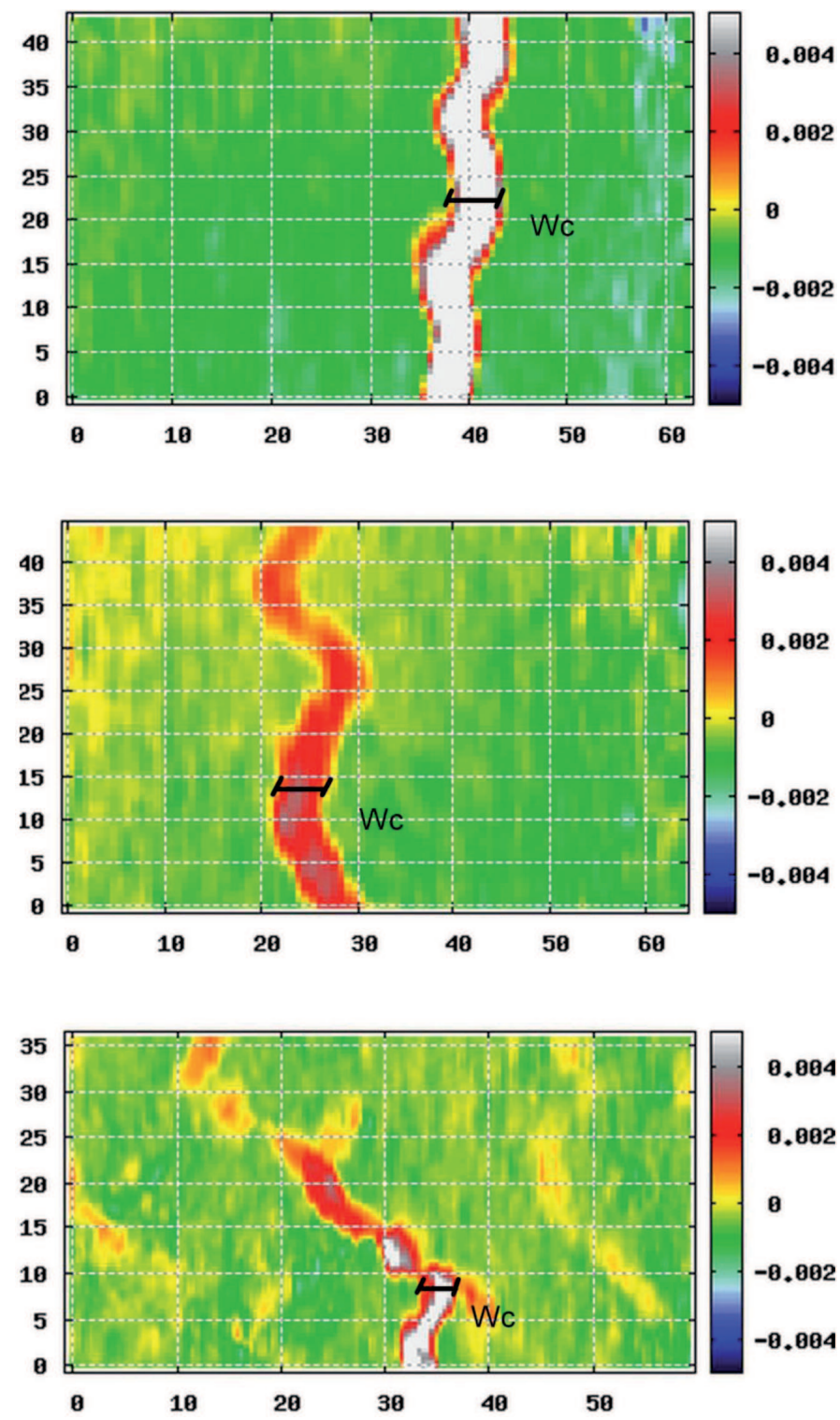

Fig. 4. Formation of localized zone with mean width of $w_{c}=3.5-4.0 \mathrm{~mm}$ directly above notch in 3 different experiments with small-size notched beam $80 \times 320 \times 40 \mathrm{~mm}^{3}$ using DIC (vertical and horizontal axes denote coordinates in [mm] and colour scales strain intensity) (Skarżyński et al. [14]). 
The ITZ was assumed to be the weakest component where damage was always initiated (Lilliu and van Mier [2], Kozicki and Tejchman [5]). The width of ITZs was assumed to be equal to $t_{b}=0-0.75 \mathrm{~mm}$. The FE-meshes included up to 560 '000 triangular elements were used. The size of finite elements was small enough to obtain objective results: $s_{a}=0.5 \mathrm{~mm}$ (aggregate), $s_{c m}=0.1-0.2 \mathrm{~mm}$ (cement matrix) and $\mathrm{s}_{I T Z}=0.1 \mathrm{~mm}$ (ITZ). The calculation time was about 2-5 days using PC with CPU Q6600 $2 \times 2.4 \mathrm{GHz}$ and $4 \mathrm{~GB}$ RAM.

Typical experimental force-deflection curves with notched beams of fine-grained concrete obtained in experiments by Le BellěGo et al. [27] and in mesoscopic FE analyses by SkarŻYŃSKi and TeJchman [10] are presented in Fig. 3. A satisfactory agreement between experimental and numerical results was obtained (note that numerical results depend on the stochastic distribution of aggregate). The maximum experimental and numerical vertical force occurred at the beam deflection of $u=0.02-0.04 \mathrm{~mm}$. In turn, Fig. 4 shows the formation of a localized zone on one side of the surface of a fine-grained small-size concrete beam above the notch from laboratory tests by SKARŻYŃSKi et al. [14] using a Digital Image Correlation (DIC) technique, which is an optical way to visualize surface displacements by successive post-processing of digital images taken at a constant time increment from a professional digital camera (based on displacements, strains can be calculated). A localized zone occurred always before the peak on the force-deflection diagram and was strongly curved. In some cases, it branched. The measured width of a localized zone above the notch increased during deformation due to concrete dilatancy (Fig. 5A) up to $w_{c}=3.5-4.0 \mathrm{~mm}\left(\leq d_{\max }\right)$ in the range of the deflection $u=0.01-0.04 \mathrm{~mm}$ until a macro-crack was created. The maximum height of a localized zone above the notch was about $h_{c}=50-55 \mathrm{~mm}$ at $u=0.04$ $\mathrm{mm}$ (Fig. 5B). The width of a localized zone did not depend upon the concrete mix type and beam size (SKARŻYŃsKi et al. [14]).

The beam was modelled as a partially homogeneous and partially heterogeneous with a meso-section in the neighbourhood of the notch to reduce the computation time (Fig. 6). Based on earlier FE calculations, the minimum width of the heterogeneous region $b_{m s}=D$ near the notch should be equal to beam height $D$ in order to obtain similar results as in the entirely heterogeneous beam (SKARŻYŃsKi and TEJCHMAN [10]). The calculated width of a localized zone above the notch was determined at the beam deflection of $u=0.15 \mathrm{~mm}$ based on the non-local softening strain measure $\bar{\varepsilon}$ (Eq. 6). As the cut-off value $\bar{\varepsilon}_{\text {min }}=0.025$ was always assumed at the maximum mid-point value of $\bar{\varepsilon}_{\max }=0.08-0.13$.

Our combined macro-mesoscopic FE simulations are similar to a two-scale approach using a Coupled Volume Method, where the size of a macro-element equals the size of a meso-call (to avoid the assumption of any size of the representative volume element, Gitman et al. [30]). However, our simulations are faster because there is no need to continuously move between 2 calculation levels (the effect of an insignificant number of finite elements in a homogeneous beam region on the computation time is practically negligible). 

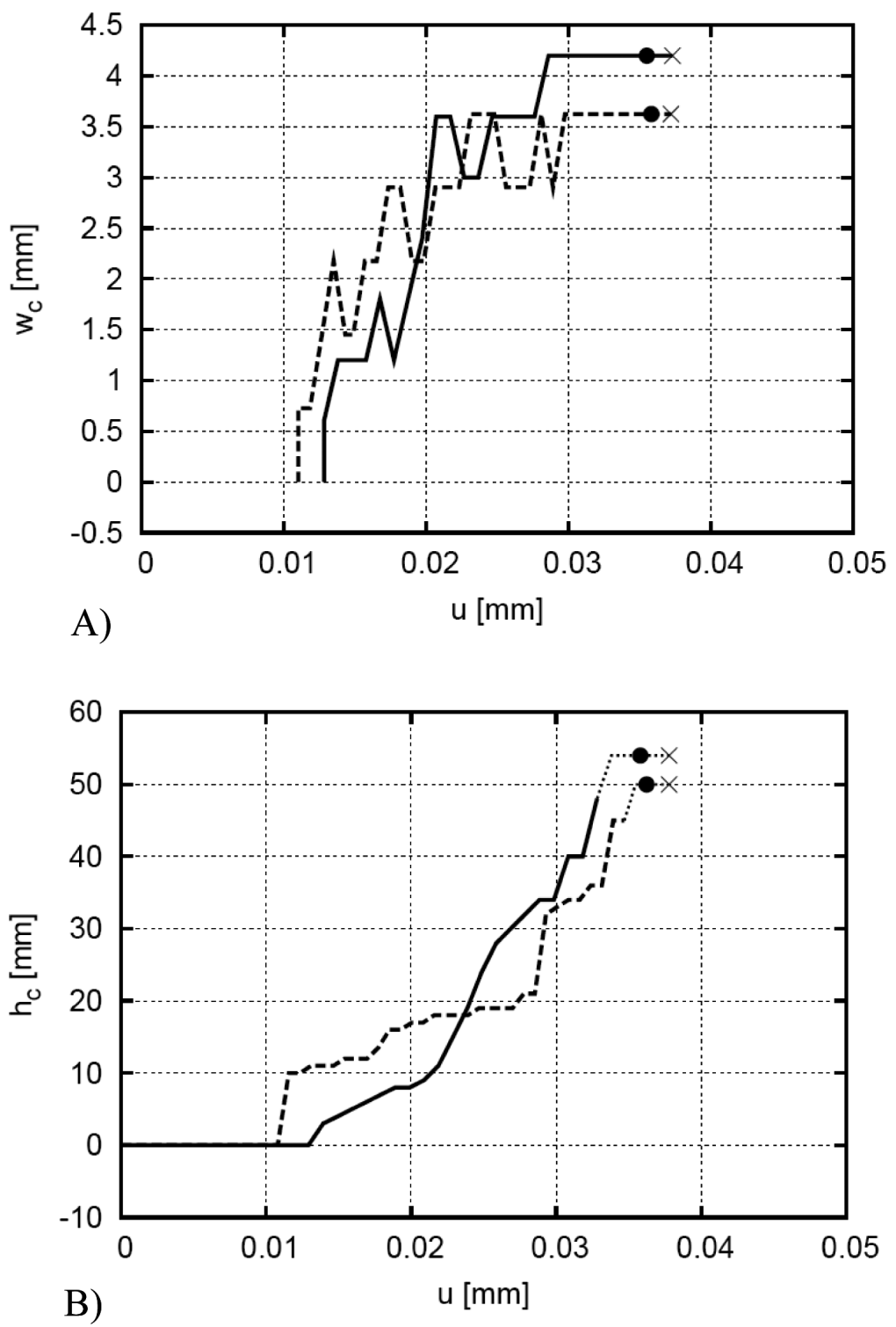

Fig. 5. Evolution of width $w_{c}$ (A) and height $h_{c}$ (B) of localized zone with deflection $u$ directly above notch in experiments with small-size notched beam $80 \times 320 \times 40 \mathrm{~mm}^{3}$ of fine-grained concrete using DIC: a) aggregate $d_{\min }=2 \mathrm{~mm}$ and $d_{\max }=8 \mathrm{~mm}, \mathrm{~b}$ ) aggregate $d_{\min }=0.25 \mathrm{~mm}$ and $d_{\max }=3 \mathrm{~mm}$ $(\times-$ maximum vertical force, $\bullet-$ formation of macro-crack). 


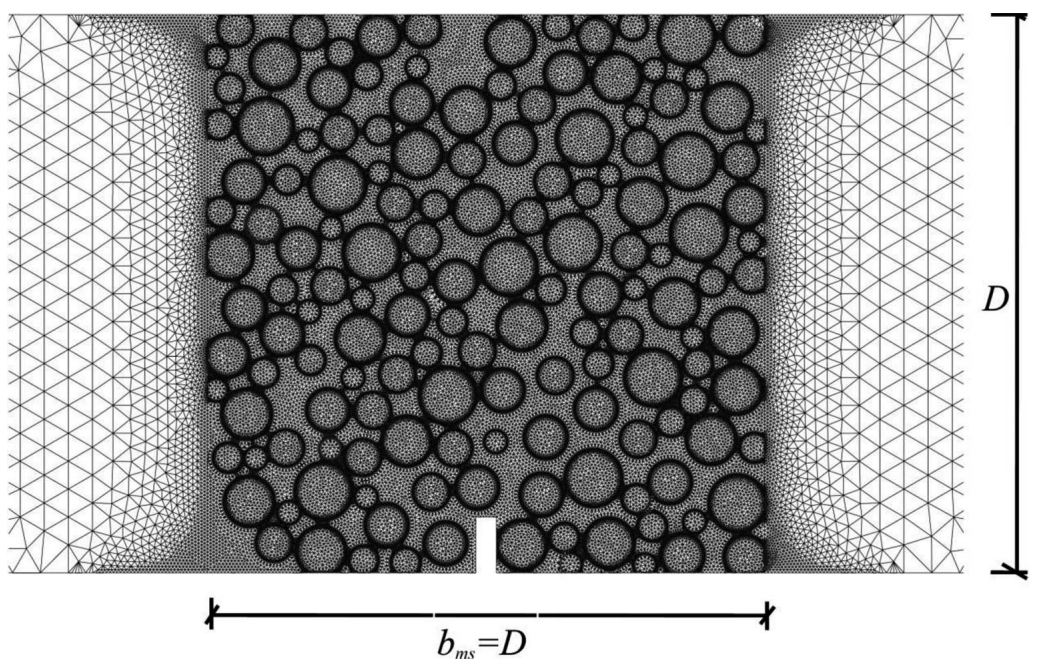

Fig. 6. FE mesh: three-phase heterogeneous concrete in notch neighbourhood with round shaped aggregate, cement matrix and interfacial transition zones ITZ and one-phase homogeneous concrete in remaining region.

\section{Mesoscopic FE RESUlts}

Below the numerical 2D effect of different parameters such as the aggregate distribution, aggregate volume, aggregate shape, aggregate stiffness, bond thickness, notch size and characteristic length on the material behaviour (load-deflection curve and strain localization) is described. The parameters were varied independently. Three different stochastic realizations were usually performed for the same case.

\subsection{EFFECt OF STOchastic AGgREGATE DISTRIBUtion}

The effect of a random distribution of round-shaped aggregate particles in the concrete beam on the force-deflection diagram and width of a localized zone is shown in Figs. 7 and 8. The aggregate volume was $\rho=45 \%$ using two aggregate size distribution curves ' $a$ ' $\left(d_{\min }=2 \mathrm{~mm}, d_{\max }=8 \mathrm{~mm}\right)$ and ' $d$ ' $\left(d_{\min }=0.25 \mathrm{~mm}, d_{\max }=3 \mathrm{~mm}\right)$ of Fig. 2 , respectively. The ITZ thickness was $t_{b}=0.25 \mathrm{~mm}$.

All stochastic force-deflection curves are obviously the same in the almost entire elastic regime. However, they are significantly different at and after the peak (Fig. 7) due to a localized zone propagating between aggregate distributed at random, which is always non-symmetric and curved (Fig. 8). The difference in the strength is about $10-20 \%$. The calculated width of a localized zone is approximately $w_{c}=4.5 \mathrm{~mm}=3 \times$ $l_{c}=9 \times s_{c m}$ independently of $d_{\max }$ or $d_{\min }$ (as in our tests, SKARżYŃsKi et al. [14]). The calculated localized zone is created at about $u / D=0.0003(u=0.024 \mathrm{~mm})$ and its width increases during the deformation process. 

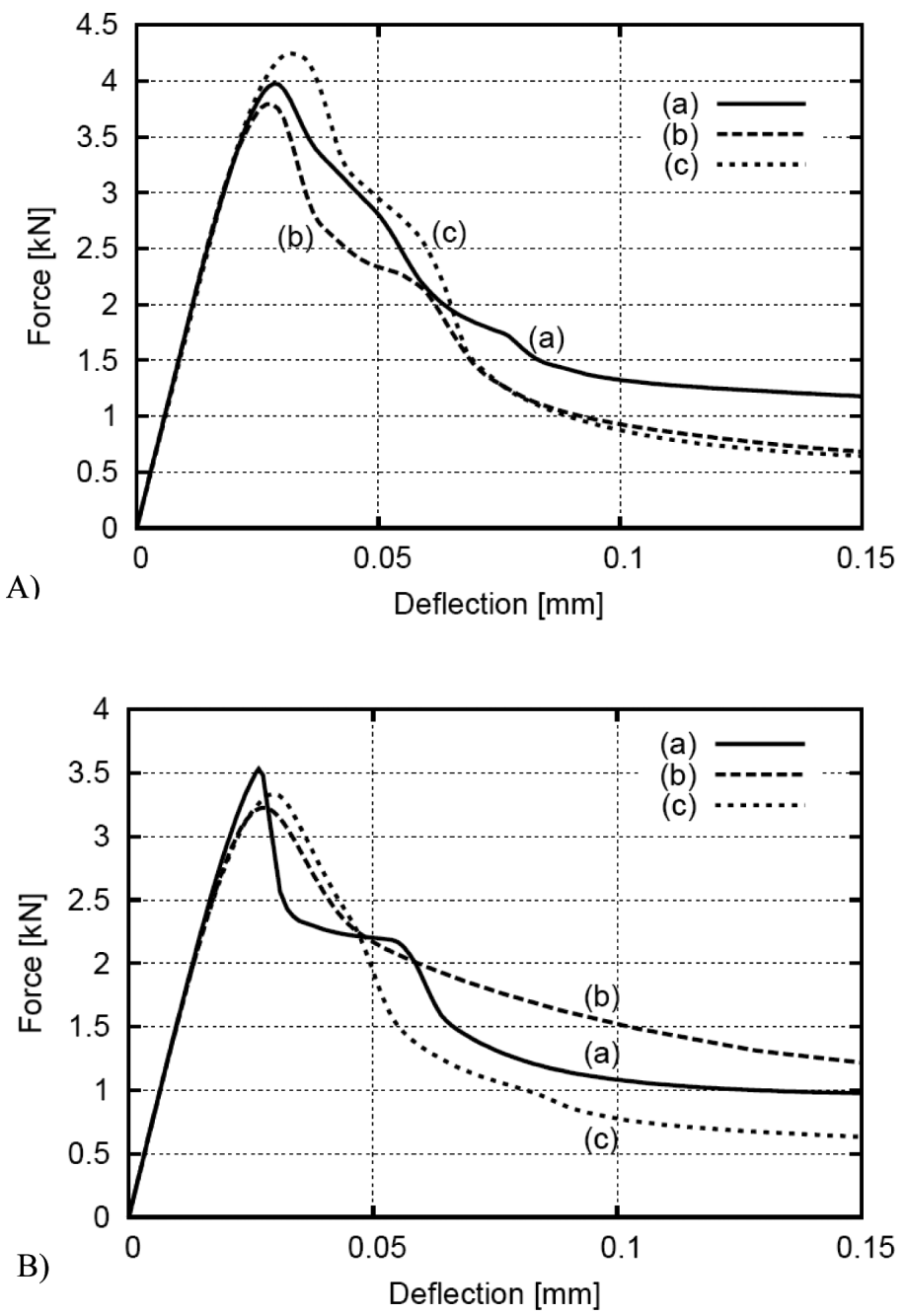

Fig. 7. Calculated force-deflection curves for fine-grained concrete beam $\left(l_{c}^{m}=1.5 \mathrm{~mm}, \rho=45 \%\right.$, $\left.t_{b}=0.25 \mathrm{~mm}\right)$ : A) with aggregate size distribution curve ' $a$ ' of Fig. $2\left(d_{\min }=2 \mathrm{~mm}\right.$ and $\left.d_{\max }=8 \mathrm{~mm}\right)$ and B) with aggregate size distribution curve ' $d$ ' of Fig. $2\left(d_{\min }=0.25 \mathrm{~mm}\right.$ and $\left.d_{\max }=3 \mathrm{~mm}\right)$ for three random distributions of circular aggregates (curves ' $a$ ', ' $b$ ' and ' $c$ '). 
a)
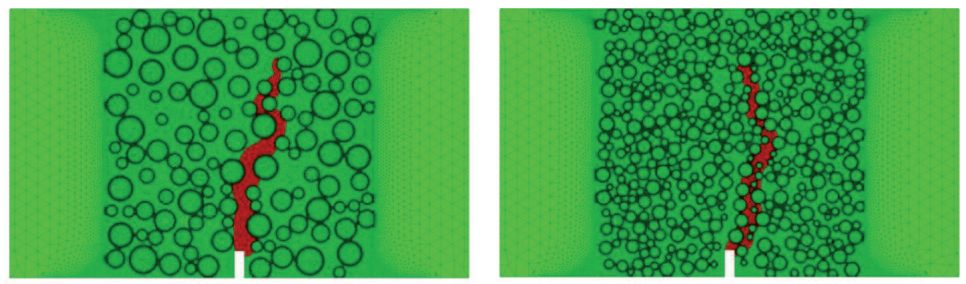

b)
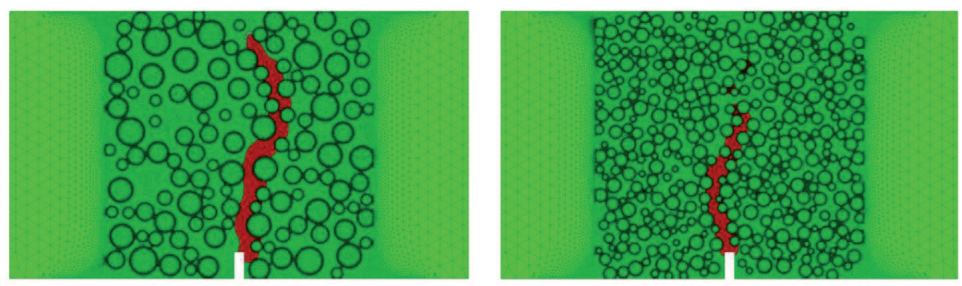

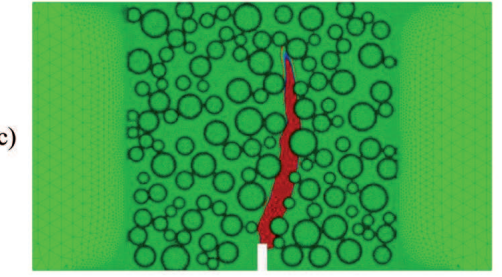

A)

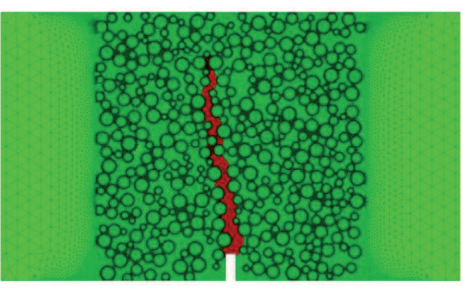

B)

Fig. 8. Calculated localized zone in fine-grained concrete beam in notch region based on distribution of non-local strain measure corresponding to load-deflection curves ' $a$ ', ' $b$ ' and ' $c$ ' of Figs.7A and 7B $\left(l_{c}^{m}=1.5 \mathrm{~mm}, \rho=45 \%, t_{b}=0.25 \mathrm{~mm}\right)$

A similar strong stochastic effect was also observed in FE calculations by GITMAN et al. [17] and He [6]. Surprisingly, a negligible stochastic effect was found in FE simulations by Kıм and AвU Az-Rub [7].

\subsection{EFFECT OF AGGREGATE SHAPE AND AGGREGATE SIZE DISTRIBUTION}

To model the effect of the aggregate shape, four different grain shapes were taken into account, namely: circular, octagonal, irregular (angular) and rhomboidal (Fig. 9) keeping always the volume fraction and centres of grains constant $\left(l_{c}^{m}=1.5 \mathrm{~mm}, \rho=60 \%\right.$, $\left.t_{b}=0.25 \mathrm{~mm}\right)$.

The aggregate shape can have a different influence on the beam ultimate strength depending upon the aggregate size distribution (Figs. 10 and 11). For the aggregate size distribution of Fig. 2a, the ultimate beam strength is the highest for rhomboidal-shaped particles and the lowest for octagonal-shaped particles (Fig. 9A, Figs. 11B and 11D). This difference equals even $30 \%$. In the case of the aggregate size distribution curve of Fig. 2b, the ultimate beam strength is similar for all assumed particle shapes (Fig. 10B). 
a)

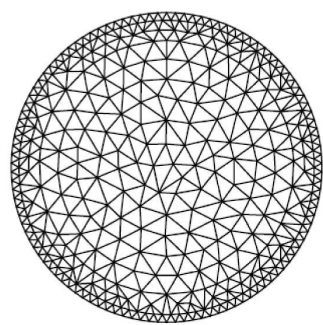

c)

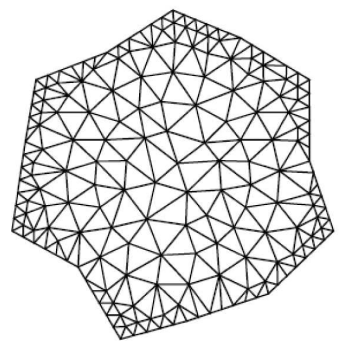

b)

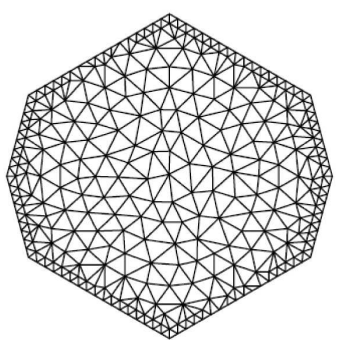

d)

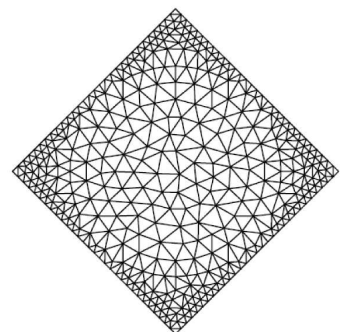

Fig. 9. Aggregate shape assumed in calculations: a) circular, b) octagonal, c) irregular (angular), d) rhomboidal.

For the aggregate size distribution of Fig. 2c, angular-shaped inclusions have the lower tensile strength than circular grains (Fig. 10C). From simulations follows that the mean tensile strength is usually higher with the larger mean grain size and the narrower grain range (Figs. 10A, 10B, 10C and 11).

The width of a localized zone equals approximately $w_{c}=3 \mathrm{~mm}$ for $\rho=60 \%$ and is not influenced by the aggregate shape, aggregate distribution, mean and maximum grain size (Fig. 12). In turn, the form of a localized zone is strongly affected by the aggregate shape contributing thus to the different strength. The calculated width of a localized zone is in good agreement with our experiments with fine-grained concrete (Figs. 4 and 5A). Our outcome is in contrast to statements by PiJauder-Cabot and BAžANT [11], and BAžANT and Он [31] wherein the width of a localized zone in usual concrete was estimated to be dependent upon $d_{\max }$. It is also in contrast to experimental results by Miнashi and Nomura [32] which showed that the width of a localized zone in usual concrete increased with increasing aggregate size. The differences between our and the experimental results (BažAnt and Oн [31], Miнashi and Nomura [32]) lie probably in a different concrete mix, specimen size and loading type. For instance, in our other tests with large reinforced concrete beams $6.0 \mathrm{~m}$ long without shear reinforcement under bending, the width of a localized zone in usual concrete was higher, i.e. $15 \mathrm{~mm}$, indicating that the macroscopic characteristic length was $l_{c}=5 \mathrm{~mm}$ (Syroka and Tejchman [33]). This problem merits further experimental and numerical investigations. 


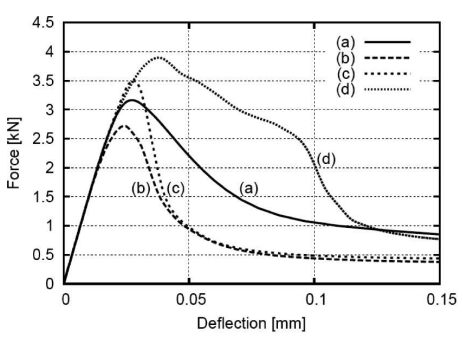

A)

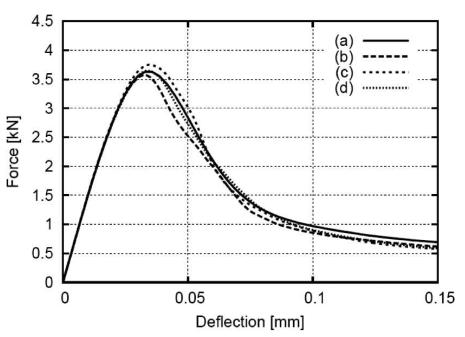

B)

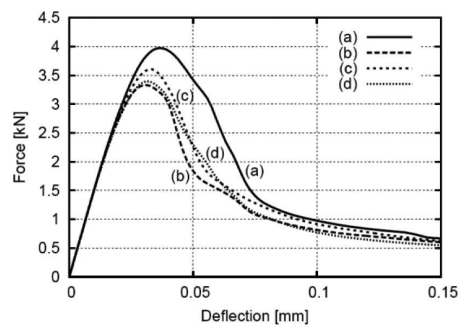

C)

Fig. 10. Calculated force-deflection curves for different aggregate shape of Fig. 9: a) circular, b) octagonal, c) irregular (angular), d) rhomboidal (fine-grained concrete beam $80 \times 320 \mathrm{~mm}^{2}$, $\left.l_{c}=1.5 \mathrm{~mm}, \rho=60 \%, t_{b}=0.25 \mathrm{~mm}\right)$ and different aggregate size distributions of Fig. 2: A) $d_{50}=2 \mathrm{~mm}$ and $d_{\text {max }}=8 \mathrm{~mm}$ (curve ' $a$ '), B) $d_{50}=4 \mathrm{~mm}$ and $d_{\max }=10 \mathrm{~mm}$ (curve ' $b$ '), C) $d_{50}=4 \mathrm{~mm}$ and $d_{\max }=6 \mathrm{~mm}$ (curve ' $c$ ').

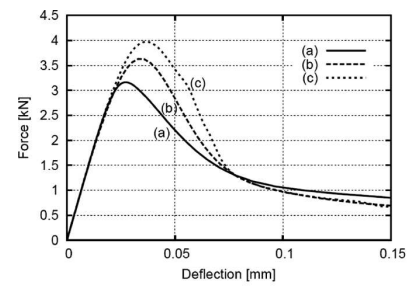

A)

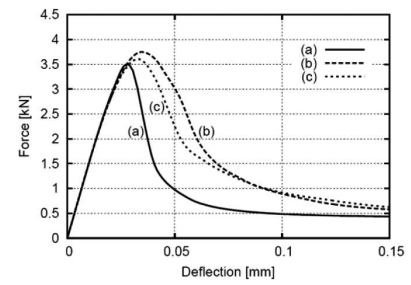

C)

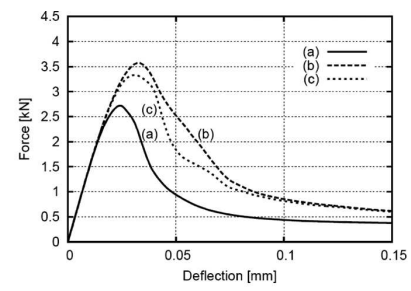

B)

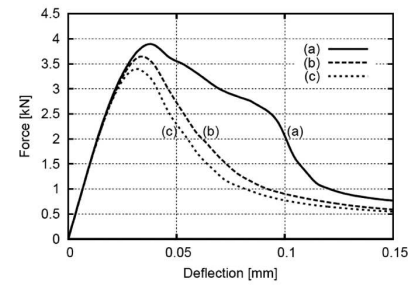

D)

Fig. 11. Calculated force-deflection curves for different aggregate shape of Fig. 9: A) circular, B) octagonal, C) irregular (angular), D) rhomboidal (fine-grained concrete beam $80 \times 320 \mathrm{~mm}^{2}$, $\left.l_{c}=1.5 \mathrm{~mm}, \rho=60 \%, t_{b}=0.25 \mathrm{~mm}\right)$ and different aggregate size distribution of Fig. 2: a) $d_{50}=2 \mathrm{~mm}$ and $d_{\max }=8 \mathrm{~mm}$ (curve ' $a$ '), b) $d_{50}=4 \mathrm{~mm}$ and $d_{\max }=10 \mathrm{~mm}$ (curve ' $b$ '), c) $d_{50}=4 \mathrm{~mm}$ and $d_{\max }=6 \mathrm{~mm}$ (curve ' $c$ '). 


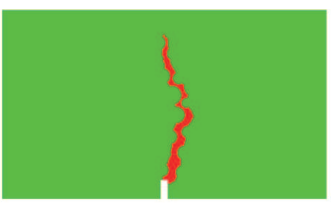

b)

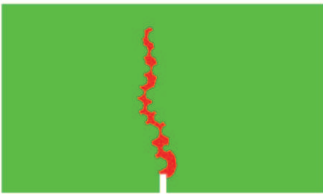

c)

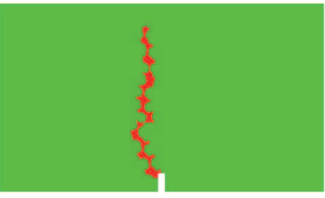

d)

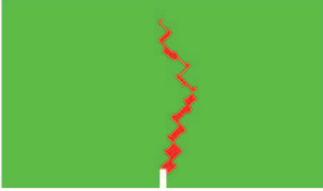

A)
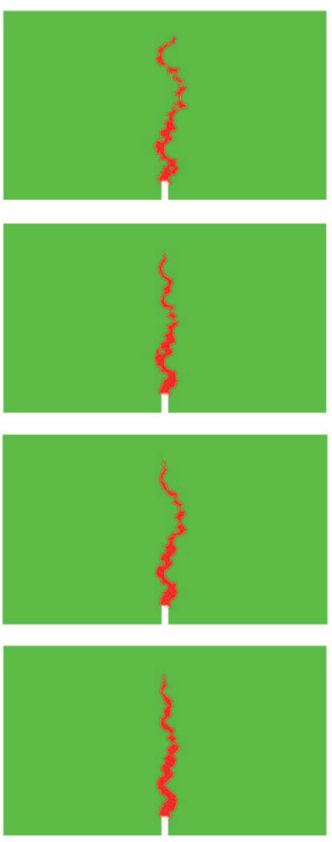

B)
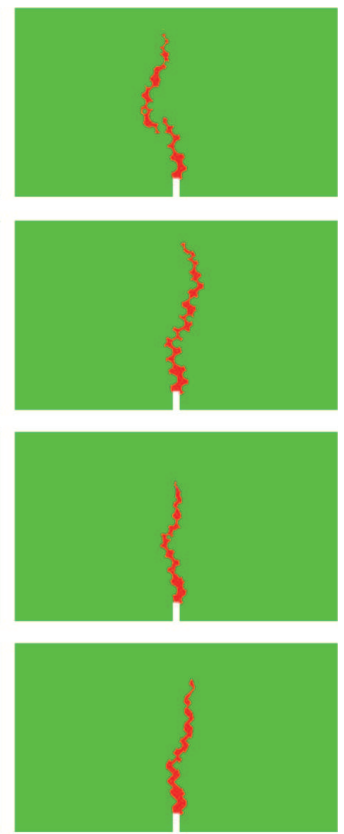

C)

Fig. 12. Calculated localized zone based on distribution of non-local strain measure in fine-grained concrete beam in notch region corresponding to load-deflection curves ' $a$ ', ' $b$ ', ' $c$ ' and ' $d$ ' of Figs. 10A, $10 \mathrm{~B}$ and 10C ( $\left.l_{c}=1.5 \mathrm{~mm}, \rho=60 \%, t_{b}=0.25 \mathrm{~mm}\right)$.

According to KIM and AвU AL-RuB [7] the aggregate shape has a weak effect on the ultimate strength of concrete and on the strain to damage-onset, but significantly affects the crack initiation, propagation and distribution. The stress concentrations at sharp edges of polygonal particles cause that the ultimate tensile strength and strain at the damage onset are the highest for circular grains model. Similar conclusions were derived by $\mathrm{HE}$ et al. [19] and He [6].

\subsection{EFFect of volume Fraction of AGGRegate}

Circular grains with the volume of $\rho=30 \%, \rho=45 \%$ and $\rho=60 \%$ were used $\left(l_{c}^{m}=1.5 \mathrm{~mm}\right.$, $t_{b}=0.25 \mathrm{~mm}$ ), Fig. 13. Figures 14 and 15 demonstrate the effect of the aggregate volume in fine-grained concrete beam with the aggregate size distributions ' $a$ ' of Fig. 2 $\left(d_{\min }=2 \mathrm{~mm}, d_{\max }=8 \mathrm{~mm}\right)$ and ' $d$ ' of Fig. $2\left(d_{\min }=0.25 \mathrm{~mm}, d_{\max }=3 \mathrm{~mm}\right)$.

In our FE simulations, the Young modulus and ultimate beam strength increase with increasing aggregate density in the range of 30\%-60\% (Fig. 14). This increase certainly depends on material parameters assumed for separated concrete phases, in particular for ITZs being always the weakest parts in concrete. 
a)

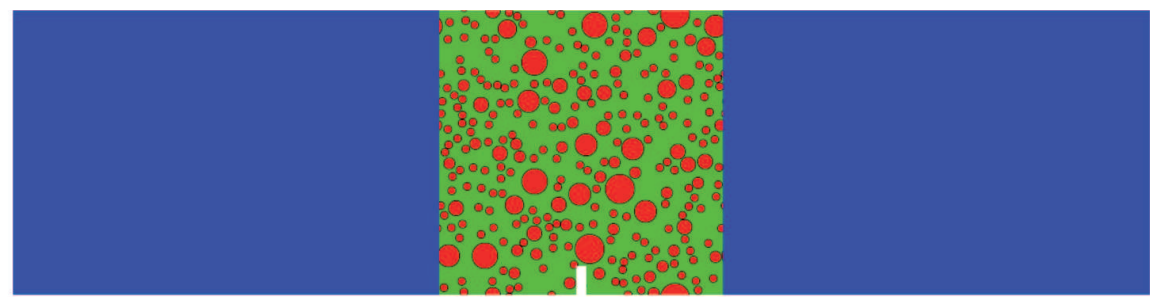

b)

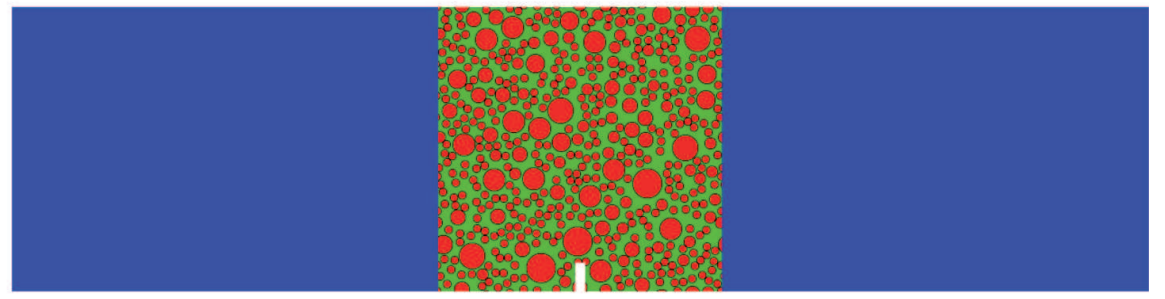

c)

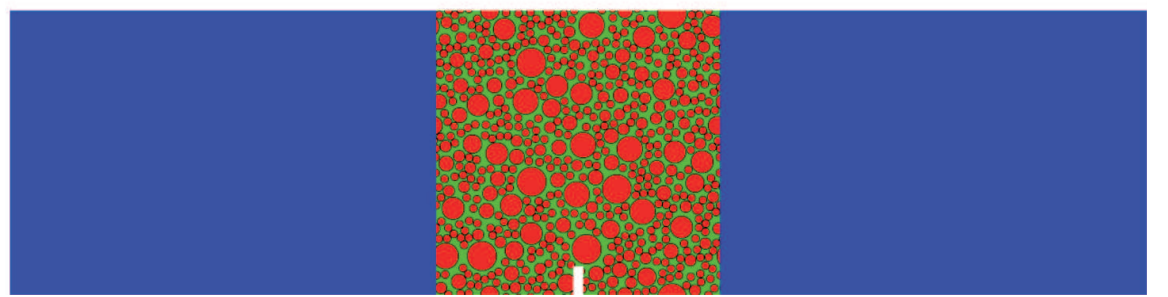

Fig. 13. Concrete beams with different volume fraction of aggregate $\rho$ in region close to notch: a) $\rho=30 \%$, b) $\rho=45 \%$ and c) $\rho=60 \%$ using grain size distribution ' $a$ ' of Fig. 2 .

The width and shape of a localized zone are influenced by the aggregate volume; a localized zone becomes narrower with increasing aggregate volume: $w_{c}=6 \mathrm{~mm}$ at $\rho=30 \%, w_{c}=4.5 \mathrm{~mm}$ at $\rho=45 \%$ and $w_{c}=3 \mathrm{~mm}$ at $\rho=60 \%$ (Fig. 15).

According to KIM and ABu AL-RuB [7] the Young modulus linearly increases with increasing aggregate volume, and the tensile strength decreases with increasing aggregate density up to $\rho=40 \%$ and increases next from $\rho=40 \%$ up to $\rho=60 \%$. The strain at the damage linearly decreases with increasing aggregate volume. He et al. [17] and $\mathrm{HE}$ [6] concluded that concrete with a higher packing density of aggregate up to $50 \%$ has a decreasing tensile strength (due to a higher number of very weak interfacial transitional zones around aggregate). It seems that the property of ITZ (stiffness, strength and width) is essential for the global strength versus $\rho$.

\subsection{EFFECT OF ITZ THICKNESS}

The interfacial transition zone (ITZ) is a special region of the cement paste around particles, which is perturbed by their presence. Its origin lies in the packing of the cement grains against the much larger aggregate which leads to a local increase in porosity (micro-voids) and a presence of smaller cement particles. A paste with lower 

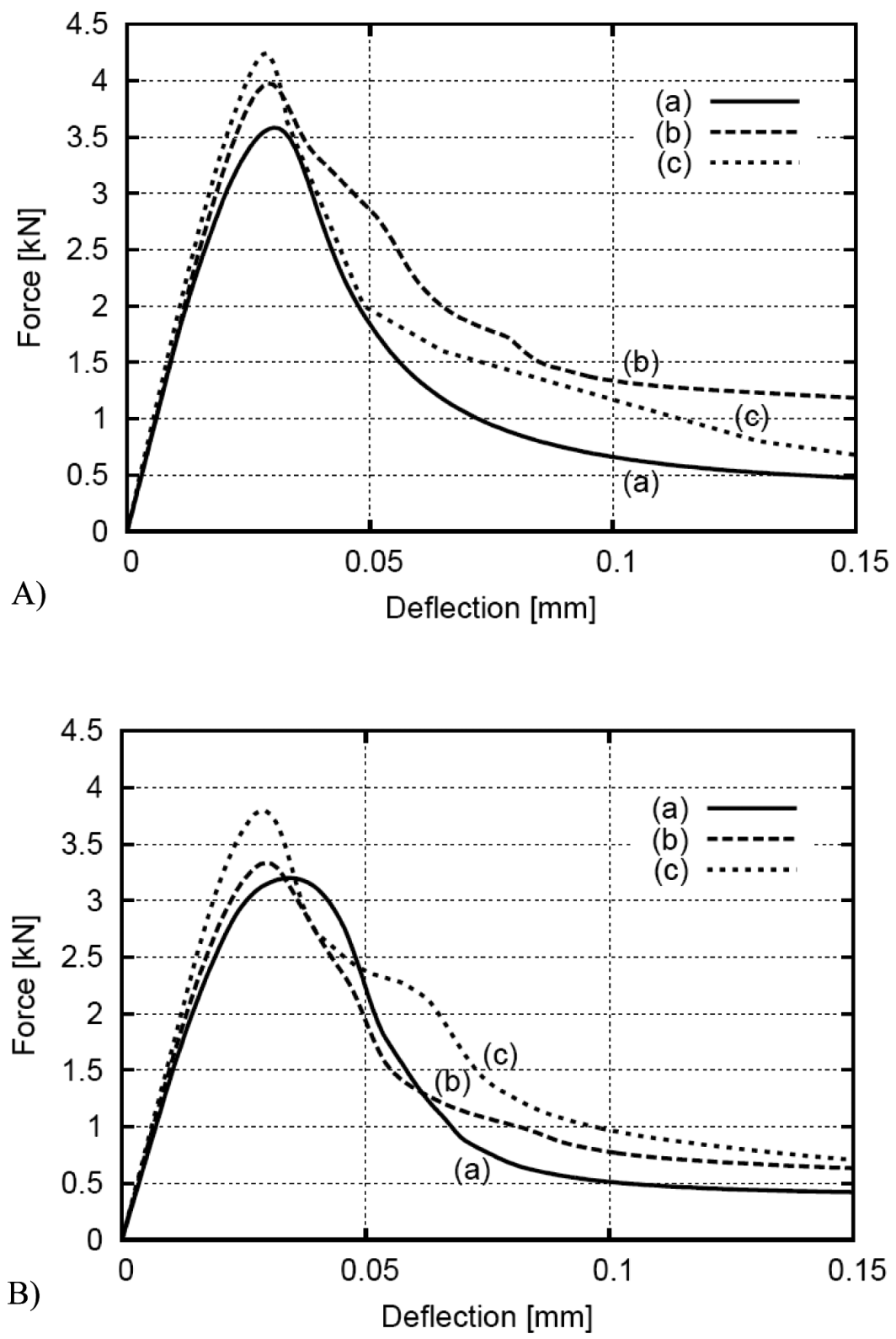

Fig. 14. Calculated load-deflection curves for different volume fractions $\rho$ of circular aggregate: a) $\rho=30 \%$, b) $\rho=45 \%$ and c) $\rho=60 \%$ (concrete beam $80 \times 320 \mathrm{~mm}^{2}, l_{c}=1.5 \mathrm{~mm}, t_{b}=0.25 \mathrm{~mm}$,

A) aggregate size distribution ' $a$ ' of Fig. $\left.2\left(d_{50}=2 \mathrm{~mm}, d_{\max }=8 \mathrm{~mm}\right), \mathrm{B}\right)$ aggregate size distribution ' $d$ ' of Fig. $2\left(d_{50}=0.5 \mathrm{~mm}, d_{\max }=3 \mathrm{~mm}\right)$. 
a)
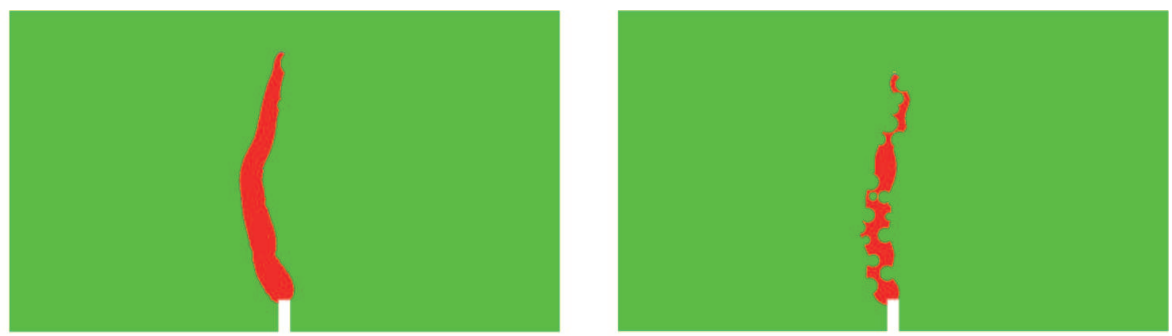

b)
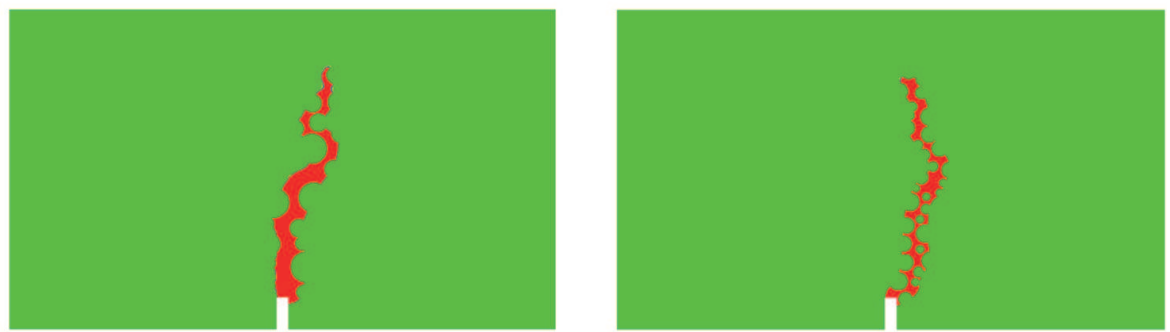

c)

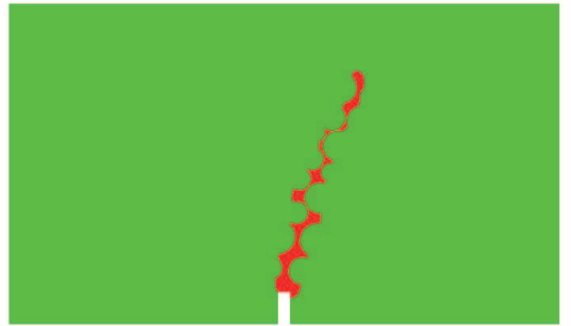

A)

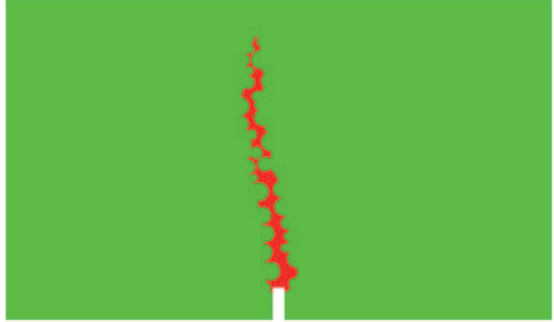

B)

Fig. 15. Calculated localized zone based on distribution of non-local strain measure in fine-grained concrete beam $80 \times 320 \mathrm{~mm}^{2}\left(l_{c}=1.5 \mathrm{~mm}, t_{b}=0.25 \mathrm{~mm}\right)$ corresponding to load-deflection curves ' $a$ ', ' $b$ ' and ' $c$ ' of Figs. 14A and 14B

$w / c$ (higher packing density) or made with finer cement particles leads to ITZ of smaller extent. This layer is highly heterogeneous and damaged and thus critical for the concrete behaviour (SRIVENER et al. [34], Mondal et al. [35]). An accurate understanding of the properties and behaviour of ITZ is one of the most important issues in the meso-scale analysis because damage is initiated at the weakest region and ITZ is just this weakest link in concrete. We assumed that ITZs have the reduced stiffness and strength as compared to the cement matrix (Tabl. 1).

Figures 16 and 17 demonstrate the effect of the ITZ thickness in a fine-grained concrete beam of Fig. 1 for circular grains with the aggregate size distribution ' $a$ ' of Fig. $2\left(d_{\min }=2 \mathrm{~mm}, d_{\max }=8 \mathrm{~mm}\right)$ assuming the aggregate volume fraction $\rho=45 \%$ and $\rho=60 \%\left(l_{c}^{m}=1.5 \mathrm{~mm}\right)$. Since there is very limited data on the thickness of ITZ, the thickness $t_{b}$ in our study was assumed to be $0 \mathrm{~mm}, 0.05 \mathrm{~mm}$ (He et al. [19], HE [6]), $0.25 \mathrm{~mm}$ (Gitman et al. [17]) and $0.75 \mathrm{~mm}$. 

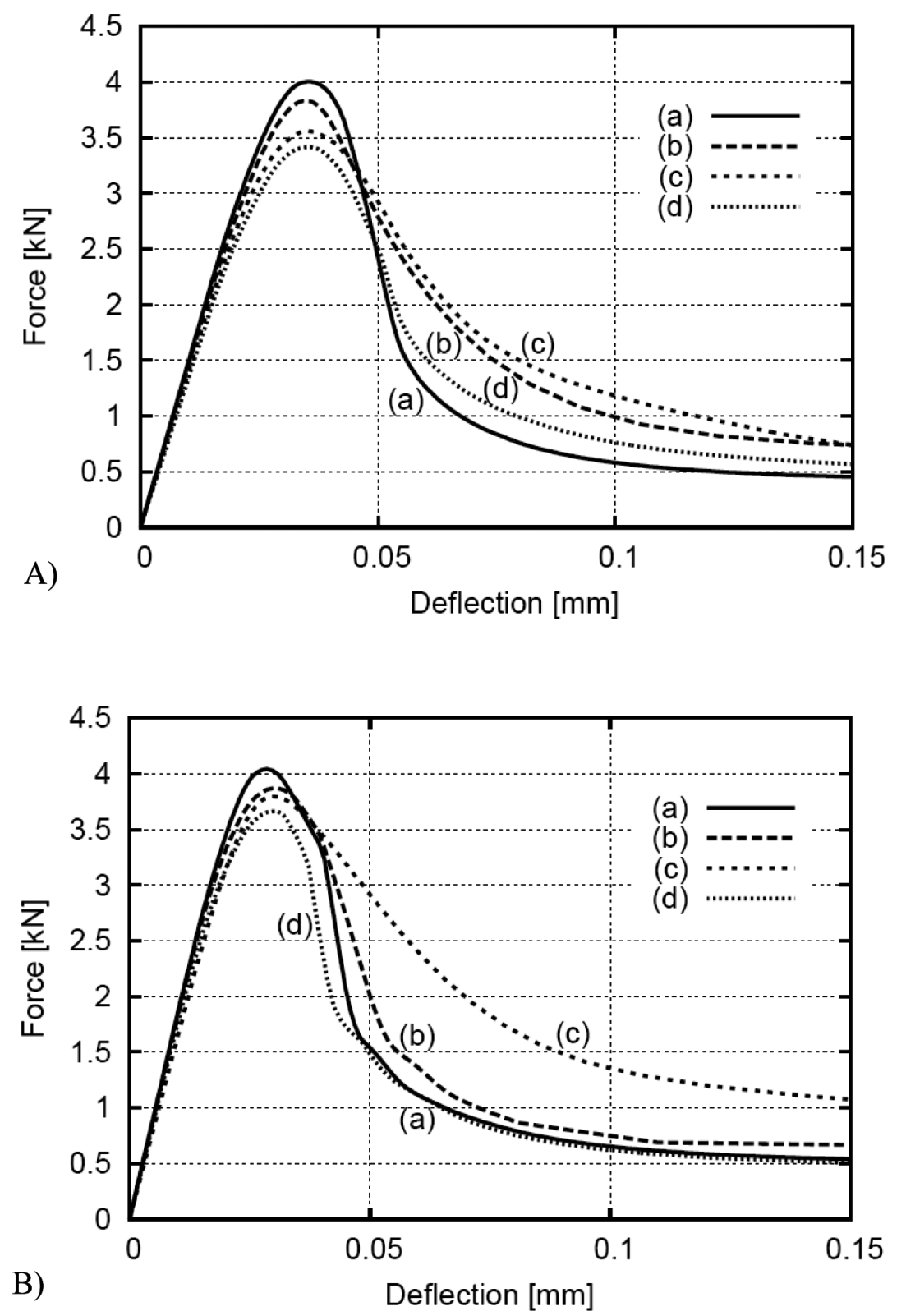

Fig. 16. Numerical effect of different ITZ thickness $t_{b}$ in FE calculations on load-deflection curve: a) $t_{b}=0 \mathrm{~mm}$, b) $t_{b}=0.05 \mathrm{~mm}$, c) $t_{b}=0.25 \mathrm{~mm}$ and d) $t_{b}=0.75 \mathrm{~mm}$, A) $\rho=45 \%$, B) $\rho=60 \%$ (fine-grained concrete beam $80 \times 320 \mathrm{~mm}^{2}, l_{c}=1.5 \mathrm{~mm}$, circular grains with size distribution ' $a$ ' of Fig. $2\left(d_{50}=2 \mathrm{~mm}, d_{\max }=8 \mathrm{~mm}\right)$. 
The results show that the thickness and strength of ITZs strongly affect both the load-displacement response and shape of localized zone. Since ITZ is the weakest phase, the ultimate beam strength decreases with increasing bond thickness (Fig. 16). This result is in agreement with those by He et al. [19], He [6] and KIM and ABu AL-Rub [7]. However, the residual strength rather increases with increasing bond thickness as in calculations by KIM and AвU AL-RUB [7]. The width of a localized zone is $w_{c}=4.5$ $\mathrm{mm}(\rho=45 \%)$ and $w_{c}=3 \mathrm{~mm}(\rho=60 \%)$ and is not affected by the ITZ size $t_{b}$ (Fig. 17).

a)
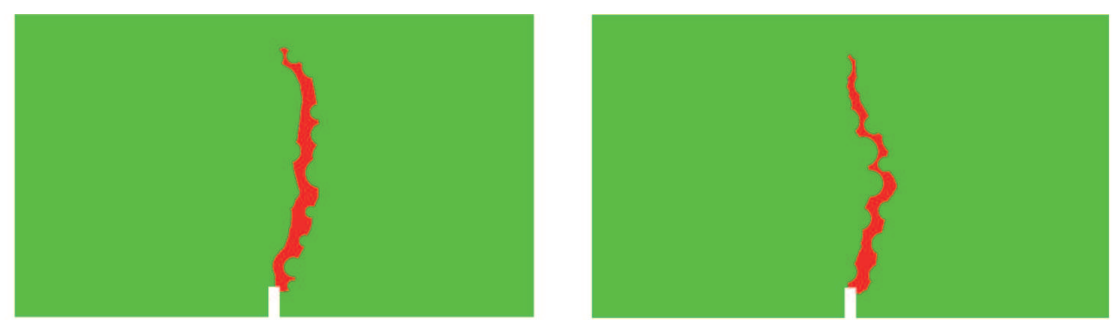

b)
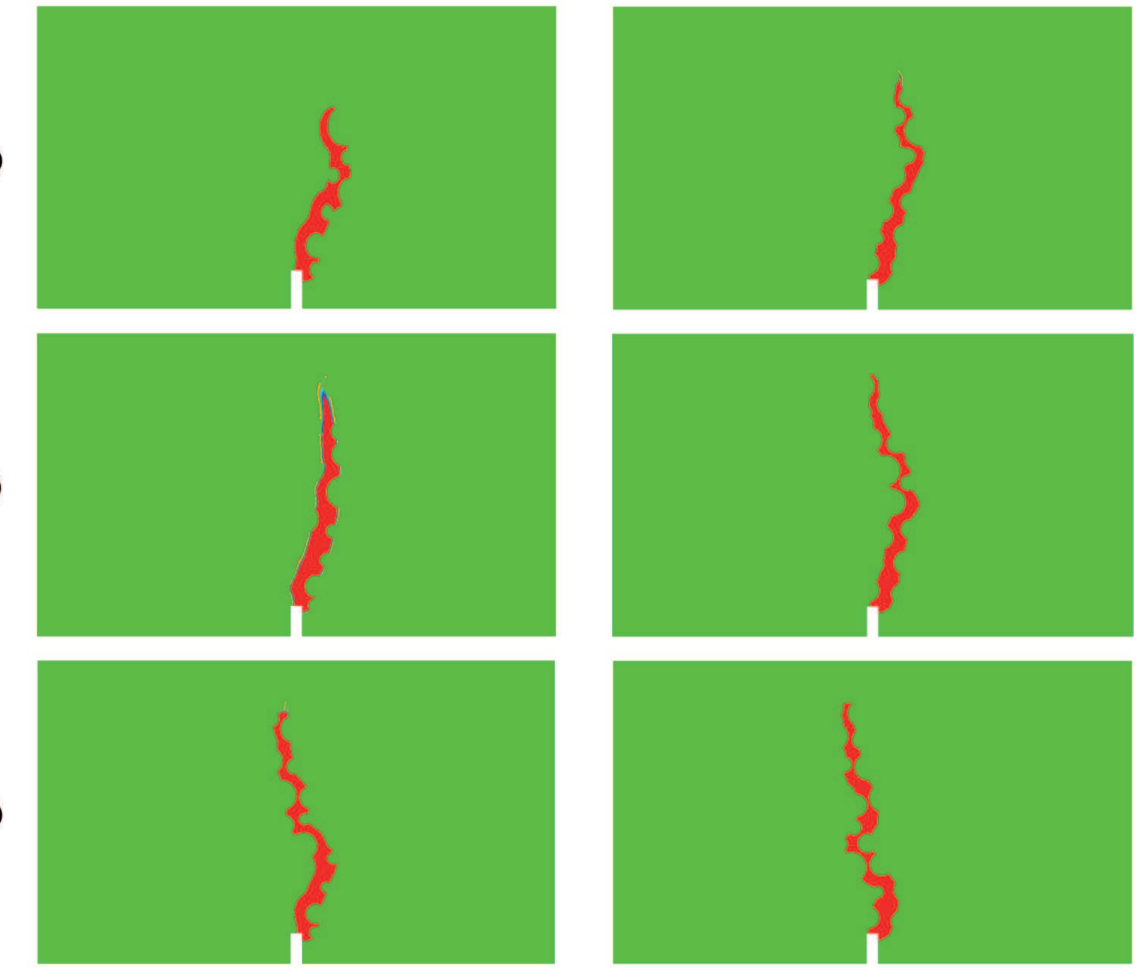

A)

B)

Fig. 17. Numerical effect of different bond thickness $t_{b}$ in FE calculations on distribution of non-local strain measure close to beam notch corresponding to load-deflection curves ' $a$ ', ' $b$ ', ' $c$ ' and ' $d$ ' of Figs. 16A and 16B. 


\subsection{EFFECT OF NOTCH SIZE}

Figures 18 and 19 demonstrate the effect of the notch size on the load-deflection diagram and strain localization in a fine-grained concrete beam with a random distribution of aggregate 'a' of Fig. $2\left(d_{\min }=2 \mathrm{~mm}\right.$ to $\left.d_{\max }=8 \mathrm{~mm}\right)$ using circular aggregate volume $\rho=30 \%$ and $\rho=60 \%\left(l_{c}^{m}=1.5 \mathrm{~mm}, t_{b}=0.25 \mathrm{~mm}\right)$. The notch size was $0 \times 0 \mathrm{~mm}^{2}, 3 \times 3$ $\mathrm{mm}^{2}$ and $6 \times 3 \mathrm{~mm}^{2}$ (width $\times$ height), respectively. The beam without notch was modelled as entirely heterogeneous to be sure that a localized zone occurs in a meso-region.
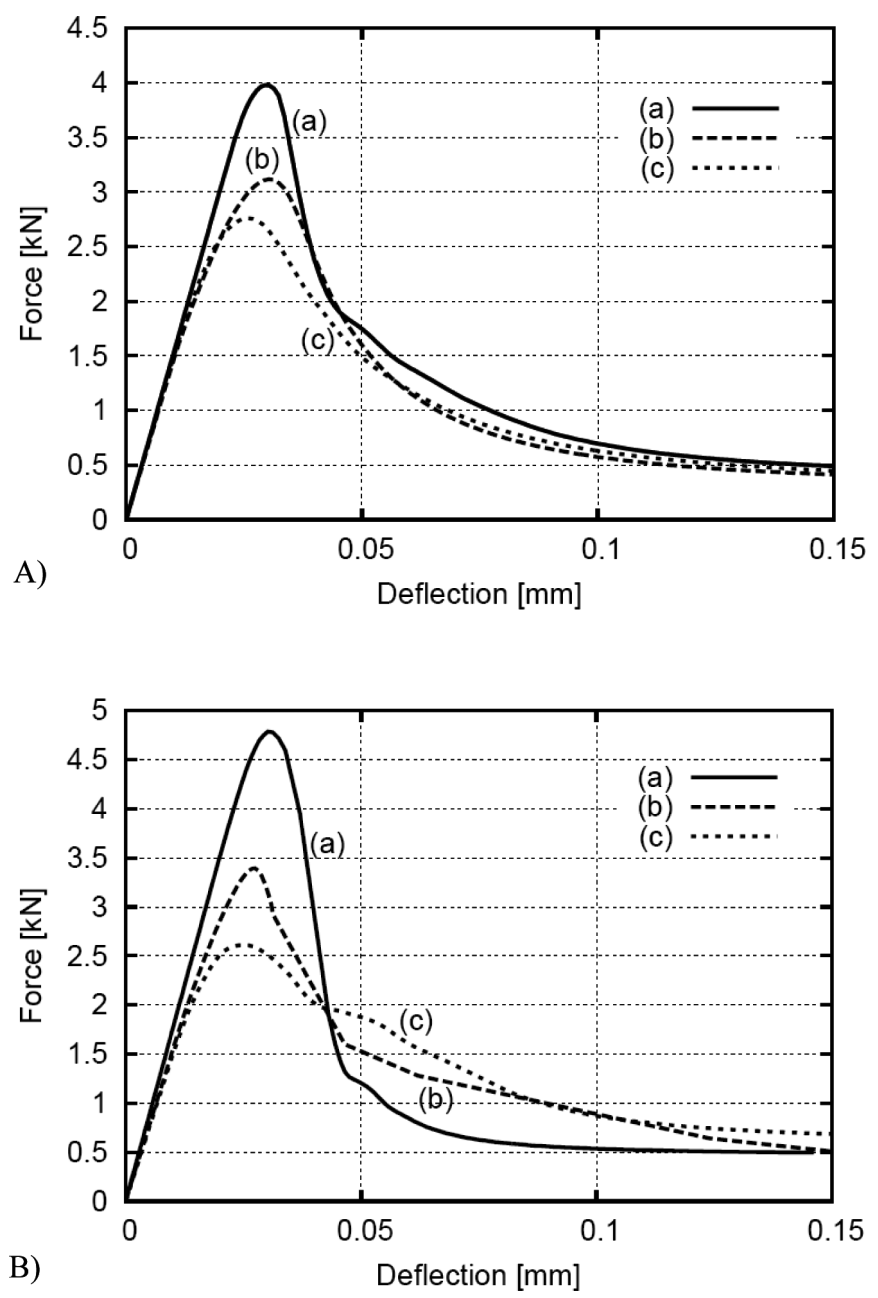

Fig. 18. Numerical effect of notch size on force-deflection curve for two different aggregate densities: a) $0 \times 0 \mathrm{~mm}^{2}$, b) $3 \times 3 \mathrm{~mm}^{2}$ and c) $6 \times 3 \mathrm{~mm}^{2}$, A) $\rho=30 \%$, B) $\rho=60 \%$ (fine-grained concrete beam $80 \times 320 \mathrm{~mm}^{2}, l_{c}=1.5 \mathrm{~mm}$, circular aggregate distribution ' $a$ ' of Fig. 2 with $d_{50}=2 \mathrm{~mm}$ and

$$
\left.d_{\max }=8 \mathrm{~mm}\right) \text {. }
$$


The ultimate beam strength is higher with decreasing notch size (Fig. 18). The notch size has no influence on the width of a localized zone $\left(w_{c}=6 \mathrm{~mm}\right.$ at $\rho=30 \%$ and $w_{c}=3 \mathrm{~mm}$ at $\rho=60 \%$ (Fig. 19).

a)
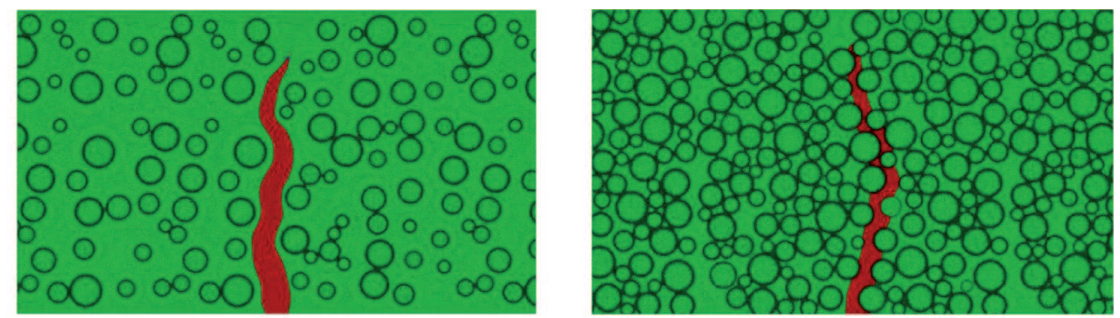

b)
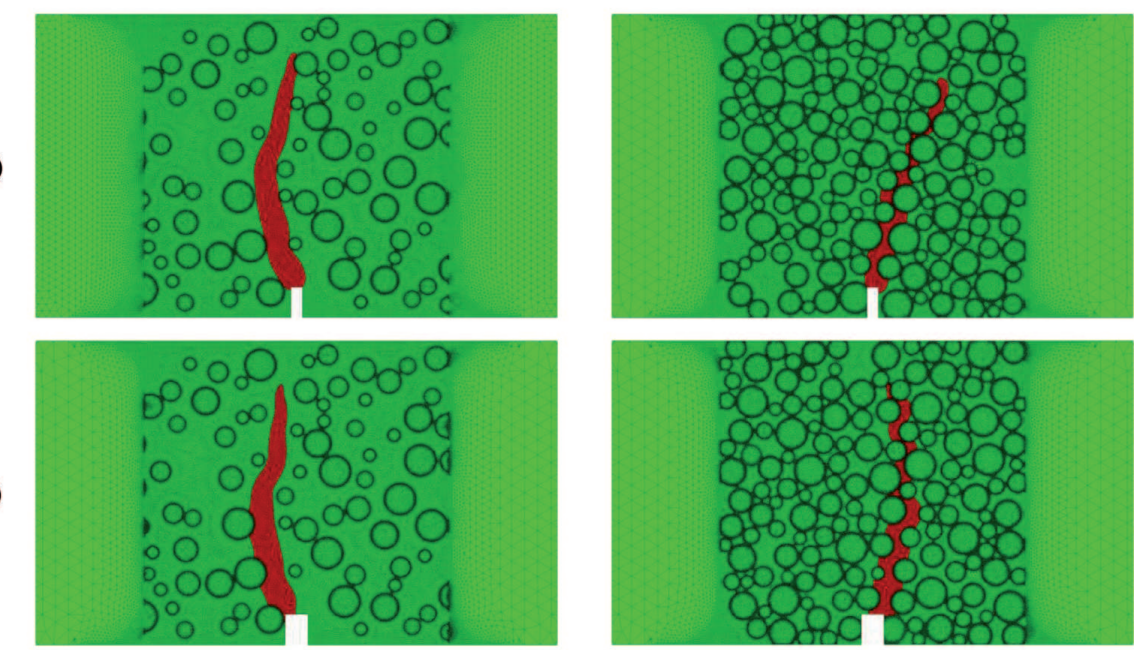

A)

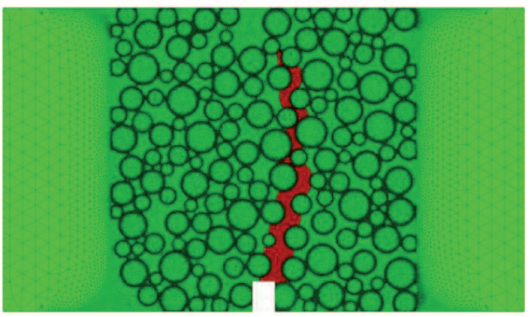

B)

Fig. 19. Numerical effect of notch size on distribution of non-local strain measure close to beam notch corresponding to load-deflection curves ' $a$ ', ' $b$ ' and ' $c$ ' of Figs.18A and 18B.

\subsection{EFFeCt OF AGGREGATE STIFFNESS}

Figure 20 shows the effect of the aggregate stiffness in a small size beam $(80 \times 320$ $\mathrm{mm}^{2}, d_{\min }=2 \mathrm{~mm}$ and $\left.d_{\max }=10 \mathrm{~mm}, \rho=60 \%, t_{b}=0.25 \mathrm{~mm}, l_{c}^{m}=1.5 \mathrm{~mm}\right)$. The calculations were carried out with weak aggregate (which had the same properties as ITZ of Tab. 1).

For the weak aggregate, a localized zone can propagate through weak grains. The vertical force is obviously smaller and the width of a localized zone is higher as compared to the results with the strong aggregate (strong aggregate $-w_{c}=3.3 \mathrm{~mm}$, weak aggregate $-w_{c}=5.8 \mathrm{~mm}$ ). 

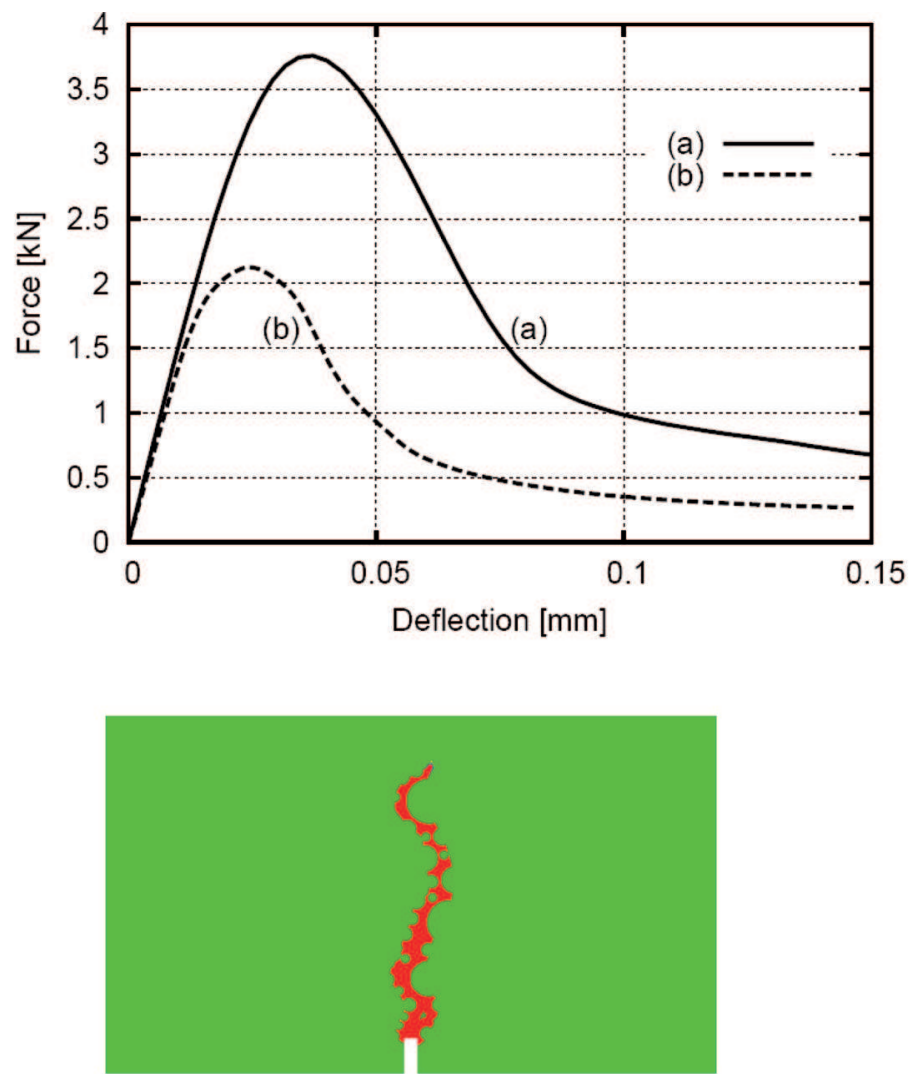

a)
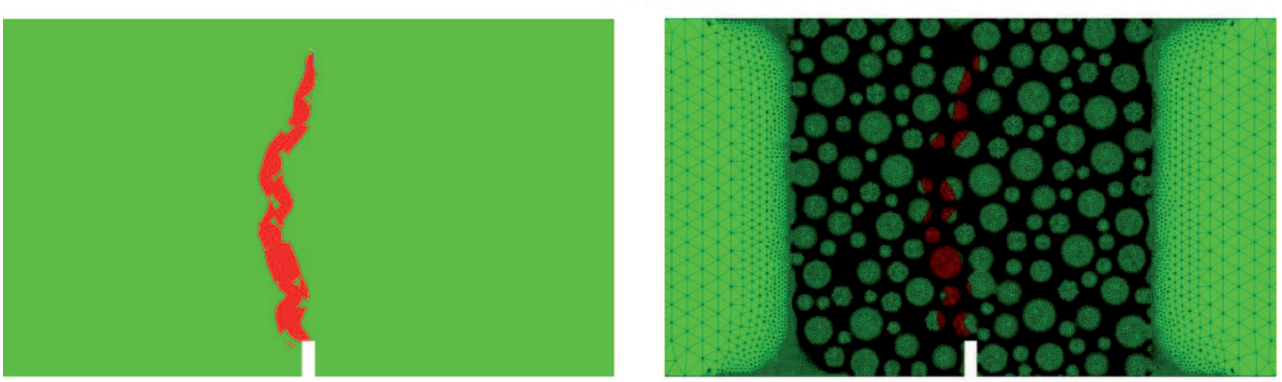

b)

Fig. 20. Effect of aggregate stiffness on force-deflection curve and distribution of non-local strain measure close to beam notch: a) strong circular aggregate, b) weak circular aggregate (fine-grained concrete beam $80 \times 320 \mathrm{~mm}^{2}, l_{c}=1.5 \mathrm{~mm}$, circular aggregate distribution ' $c$ ' of Fig. 2 with $d_{50}=4 \mathrm{~mm}$ and $d_{\max }=10 \mathrm{~mm}, \rho=60 \%$ ). 


\subsection{EFFECT OF CHARACTERISTIC LENGTH OF MICRO-STRUCTURE}

The effect of a characteristic length of micro-structure on the load-deflection diagram and strain localization is shown in Figs. 21 and 22 using the same stochastic distribution of circular aggregate $\left(l_{c}\right.$ changed between $0.5 \mathrm{~mm}$ and $\left.5 \mathrm{~mm}\right)$.

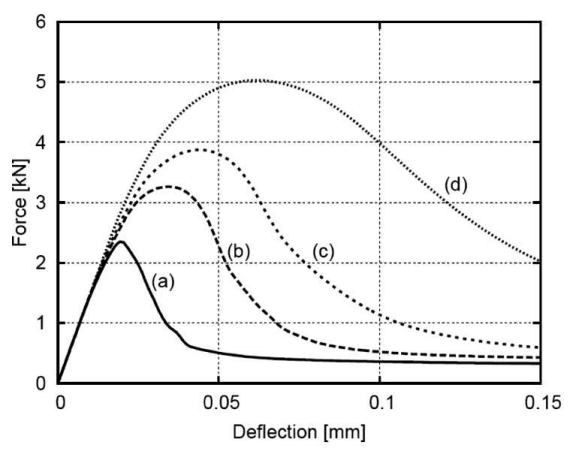

A)

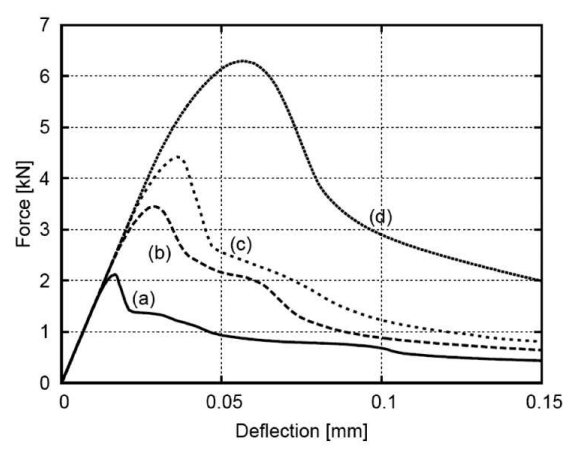

B)

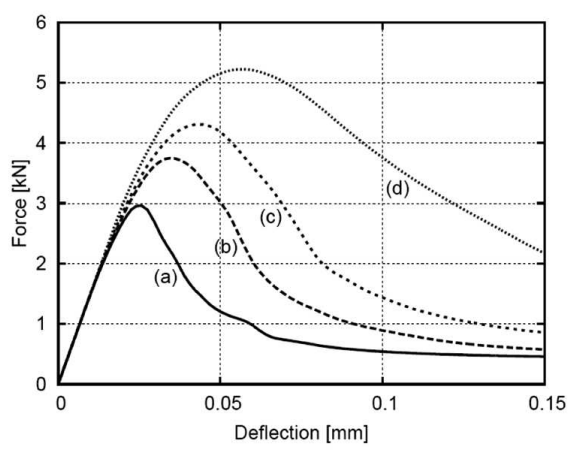

C)

Fig. 21. Calculated load-deflection curves for different characteristic lengths $l_{c}$ : a) $l_{c}=0.5 \mathrm{~mm}$,

b) $\left.l_{c}=1.5 \mathrm{~mm}, \mathrm{c}\right) l_{c}=2.5 \mathrm{~mm}$ and d) $l_{c}=5 \mathrm{~mm}$ (concrete beam $80 \times 320 \mathrm{~mm}^{2}$, ITZ thickness $t_{b}=0.25 \mathrm{~mm}$ ), A) volume fraction of circular aggregate $\rho=30 \%$ (aggregate distribution ' $d$ ' of Fig. 2 with $d_{50}=0.5 \mathrm{~mm}$ and $d_{\max }=3 \mathrm{~mm}$ ), B) volume fraction of circular aggregate $\rho=45 \%$ (aggregate distribution ' $a$ ' of Fig. 2 with $d_{50}=2 \mathrm{~mm}$ and $d_{\max }=8 \mathrm{~mm}$ ), C) volume fraction of angular aggregate $\rho=60 \%$ (aggregate distribution ' $b$ ' of Fig. 2 with $d_{50}=4 \mathrm{~mm}$ and $d_{\max }=10 \mathrm{~mm}$ ).

With increasing characteristic length, both beam strength and width of a localized zone strongly increase since the material softening decreases and material becomes more ductile. A pronounced deterministic size effect occurs. A localized zone propagating in a cement matrix between aggregate grains is strongly curved at $l_{c}^{m}=0.5-2.5 \mathrm{~mm}$, where as it becomes more straight at $l_{c}^{m}>2.5 \mathrm{~mm}$. It is about: $w_{c}=2.9-17.6 \mathrm{~mm}=(3.5-5.9) \times$ $l_{c}^{m}=(5.8-35.2) \times d_{\min }$ at $\rho=30 \%, w_{c}=2.5-16.7 \mathrm{~mm}=(3.0-5.0) \times l_{c}^{m}=(1.25-8.35) \times d_{\min }$ at $\rho=45 \%$ and $w_{c}=2.4-13.9 \mathrm{~mm}=(2.3-4.7) \times l_{c}^{m}=(0.6-3.47) \times d_{\min }$ at $\rho=60 \%$ (Tab. 2). It 
a)

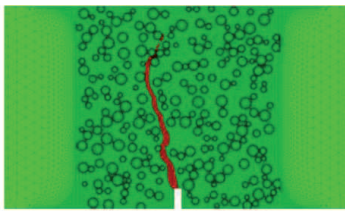

b)

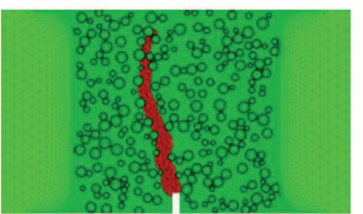

c)

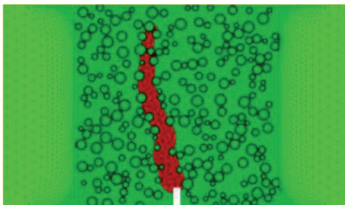

d)

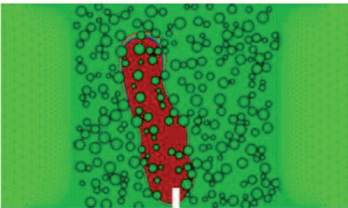

A)
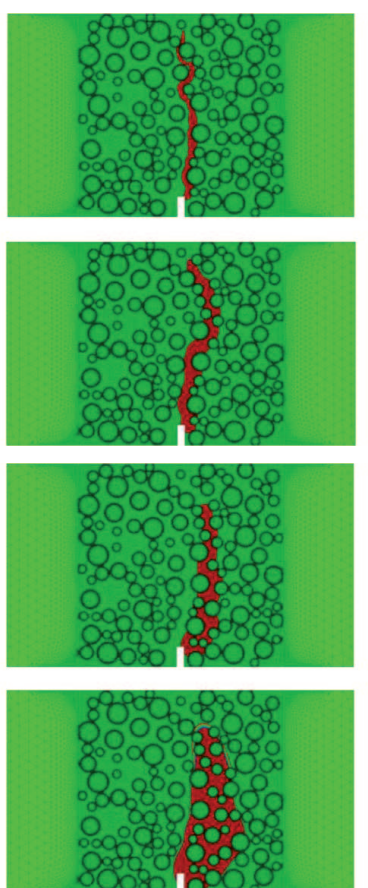

B)
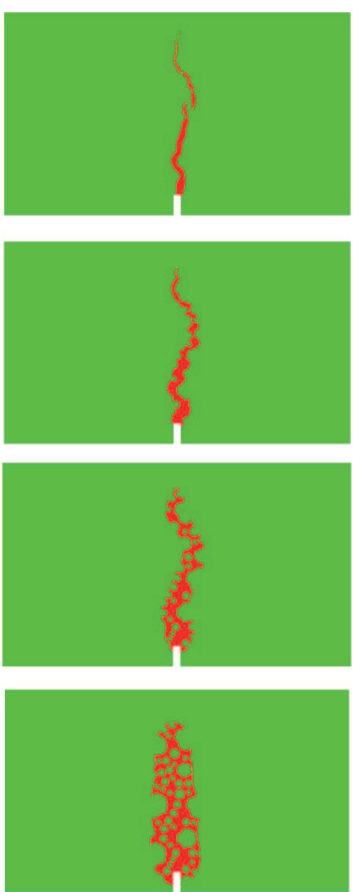

C)

Fig. 22. Calculated localized zone based on distribution of non-local strain measure for different characteristic lengths $l_{c}$ : a) $l_{c}=0.5 \mathrm{~mm}$, b) $l_{c}=1.5 \mathrm{~mm}$, c) $l_{c}=2.5 \mathrm{~mm}$ and d) $l_{c}=5 \mathrm{~mm}$ (concrete beam $80 \times 320 \mathrm{~mm}^{2}$, bond thickness $t_{b}=0.25 \mathrm{~mm}$ ), A) volume fraction of circular aggregate $\rho=30 \%$ (aggregate distribution ' $d$ ' of Fig. 2 with $d_{50}=0.5 \mathrm{~mm}$ and $d_{\max }=3 \mathrm{~mm}$ ), B) volume fraction of circular aggregate $\rho=45 \%$ (aggregate distribution ' $a$ ' of Fig. 2 with $d_{50}=2 \mathrm{~mm}$ and $d_{\max }=8 \mathrm{~mm}$ ), C) volume fraction of angular aggregate $\rho=60 \%$ (aggregate distribution ' $b$ ' of Fig. 2 with $d_{50}=4 \mathrm{~mm}$ and $d_{\max }=10 \mathrm{~mm}$ ).

always decreases with increasing $\rho$ (Tab. 2). A characteristic length of micro-structure is not uniquely connected to the aggregate size.

Table 2

Calculated width of localized zone with different characteristic length $l_{c}$ with volume fraction of aggregate $\rho$.

\begin{tabular}{|c|c|c|c|c|c|c|}
\hline \multirow{2}{*}{ Characteristic length $\boldsymbol{l}_{\mathbf{c}}$} & \multicolumn{5}{|c|}{$\begin{array}{c}\text { Width of localized zone } \boldsymbol{w}_{\mathbf{c}} \text { [mm] } \\
\text { for different volume fraction of aggregate } \rho\end{array}$} \\
\cline { 2 - 7 } & \multicolumn{2}{|c|}{$\rho=30 \%$} & \multicolumn{2}{c|}{$\rho=45 \%$} & \multicolumn{2}{c|}{$\rho=60 \%$} \\
\hline $0.5 \mathrm{~mm}$ & 2.9 & $5.9 \times l_{c}$ & 2.5 & $5.0 \times l_{c}$ & 2.4 & $4.7 \times l_{c}$ \\
\hline $1.5 \mathrm{~mm}$ & 6.2 & $4.1 \times l_{c}$ & 4.5 & $3.0 \times l_{c}$ & 3.5 & $2.3 \times l_{c}$ \\
\hline $2.5 \mathrm{~mm}$ & 9.3 & $3.7 \times l_{c}$ & 8.7 & $3.5 \times l_{c}$ & 6.9 & $2.7 \times l_{c}$ \\
\hline $5.0 \mathrm{~mm}$ & 17.6 & $3.5 \times l_{c}$ & 16.7 & $3.4 \times l_{c}$ & 13.9 & $2.8 \times l_{c}$ \\
\hline
\end{tabular}



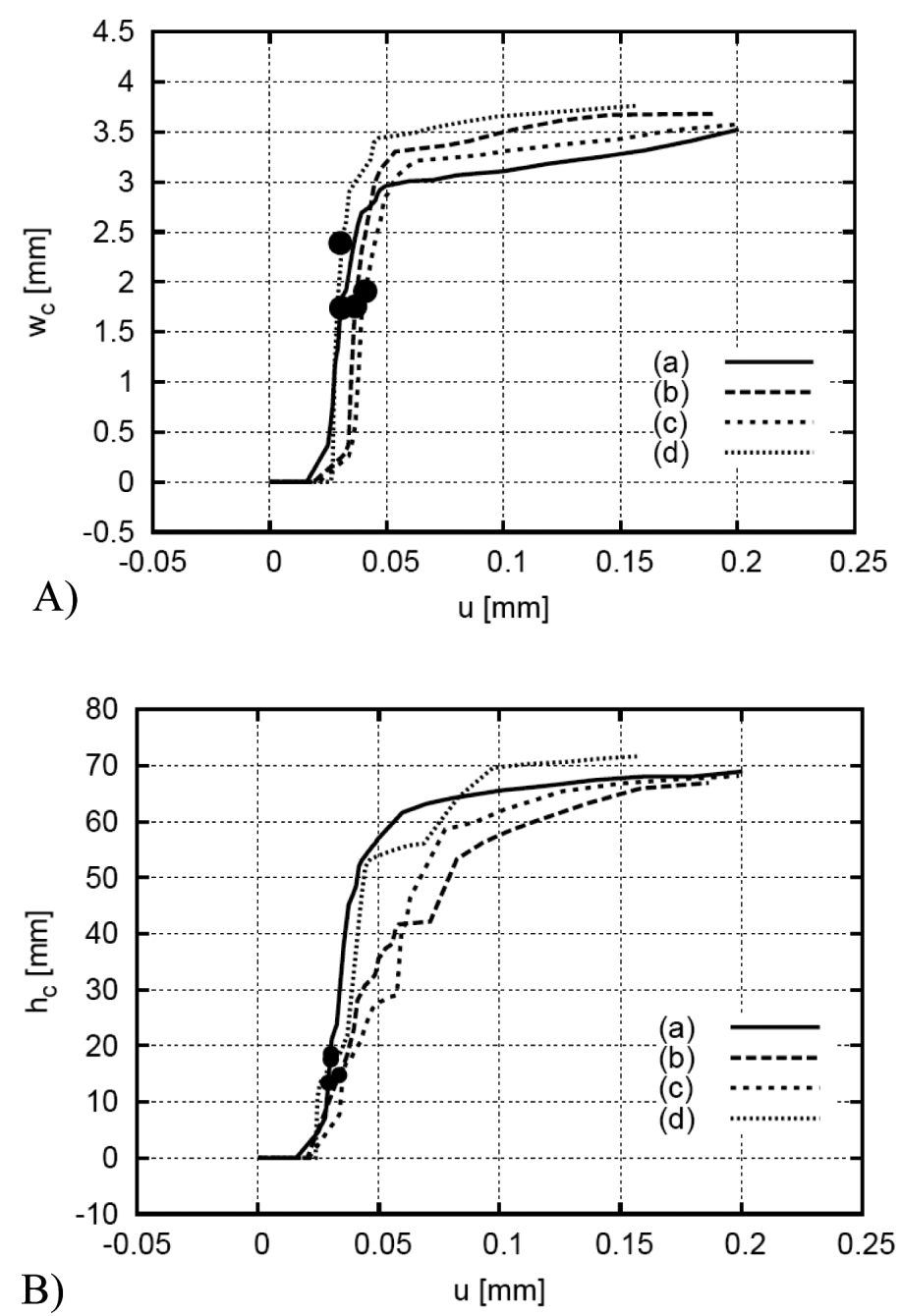

Fig. 23. The calculated evolution of width (A) $w_{c}$ and height $h_{c}(\mathrm{~B})$ of localized zone versus beam deflection $u$ : a) aggregate distribution ' $a$ ' of Fig. 2 with $d_{50}=2 \mathrm{~mm}$ and $d_{\max }=8 \mathrm{~mm}$, irregular aggregate, $\rho=60 \%, l_{c}=1.5 \mathrm{~mm}, \mathrm{~b}$ ) aggregate distribution ' $b$ ' of Fig. 2 with $d_{50}=4 \mathrm{~mm}$ and $d_{\max }=10 \mathrm{~mm}$, octagonal aggregate, $\left.\rho=60 \%, l_{c}=1.5 \mathrm{~mm}, \mathrm{c}\right)$ aggregate distribution ' $c$ ' of Fig. 2 with $d_{50}=4 \mathrm{~mm}$ and $d_{\max }=6 \mathrm{~mm}$, circular aggregate, $\rho=60 \%, l_{c}=1.5 \mathrm{~mm}, \mathrm{~d}$ ) aggregate distribution ' $a$ ' of Fig. 2 with $d_{50}=2 \mathrm{~mm}$ and $d_{\max }=8 \mathrm{~mm}$, circular aggregate, $\rho=60 \%$, beam without notch, $l_{c}=1.5 \mathrm{~mm}$ $(\bullet-$ maximum vertical force).

Finally, Fig. 23 shows the evolution of the width and height of the localized zone from FE calculations. The FE results of Fig. 23 are similar as in the experiments (Fig. 5). The calculated maximum width is $3.25 \mathrm{~mm}$ (3.5-4.0 $\mathrm{mm}$ in tests) and height $55 \mathrm{~mm}(50-55 \mathrm{~mm}$ in tests) at $u=0.2 \mathrm{~mm}$. The calculated localized zone strongly forms 
(linearly) before and after the maximum vertical force in the range of $u=0.025-0.05 \mathrm{~mm}$ (width) and of $u=0.025-0.1 \mathrm{~mm}$ (length). The mean propagation rate of the calculated localized zone versus the beam deflection is similar as in experiments, although is more uniform (Fig. 24). In the experiments, a macro-crack occurred at about $u=0.04$ $\mathrm{mm}$, which cannot be captured by our model. In order to numerically describe a macro-crack, a discontinuous approach has to be used (e.g. XFEM or cohesive crack model [37], [38], [39]).

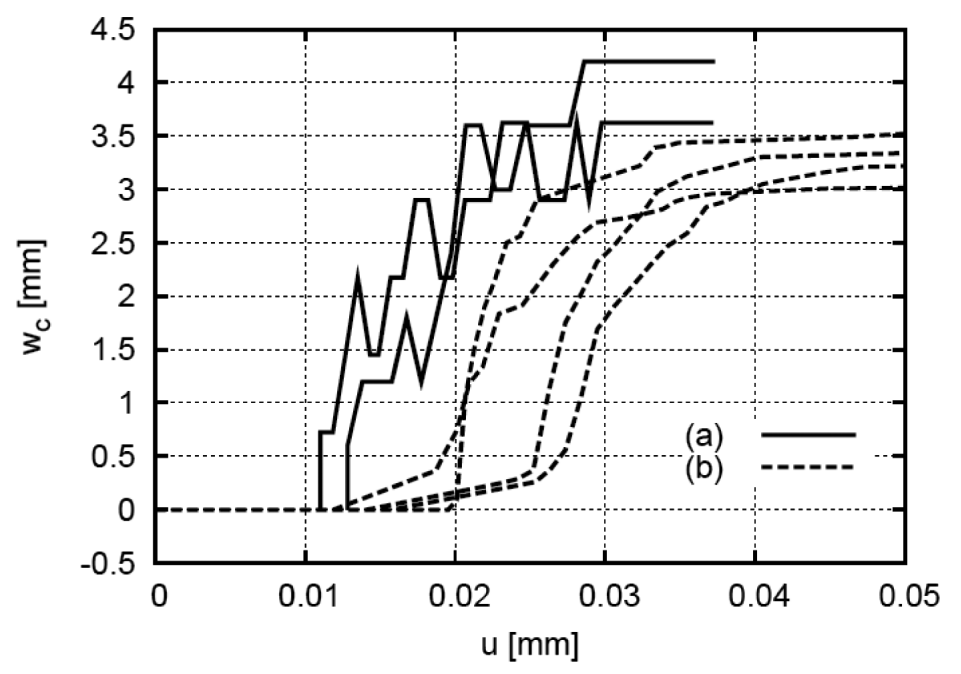

Fig. 24. Comparison between measured (a) and calculated (b) evolution of width of localized zone $w_{c}$ versus beam deflection $u$ (maximum vertical force occurs at deflection $u=0.035 \mathrm{~mm}$ )

\section{Conclusions}

A meso-scale numerical model was used to analyse the behaviour of fine-grained concrete beams. The FE-calculations revealed that an isotropic damage continuum model enhanced by a characteristic length of micro-structure is able to properly capture the evolution of strain localization in a concrete beam under tensile loading, where concrete was treated as a heterogeneous three-phase material composed of aggregate, cement matrix and ITZs. The model provides valuable insights into the material behaviour at the meso-scale strongly affecting its overall mechanical behaviour at the macro-scale.

The following conclusions can be drawn from two-dimensional calculations with notched fine-grained concrete beams under quasi-static three-point bending (by neglecting smaller aggregate):

- material micro-structure at meso-scale has to be taken into account in calculations of strain localization to obtain a proper shape of a propagating localized zone, 
- the calculated strength, width and shape of a localized zone are in a satisfactory agreement with our size effect experiments when the characteristic length of micro-structure is $1.5 \mathrm{~mm}$,

- tensile damage is initiated first in the ITZ region. This region is found to have a significant impact on the fracture behaviour and strength of concrete,

- the load-displacement evolutions strongly depend on material parameters assumed for separated concrete phases and a statistical distribution of aggregate. The ultimate beam strength certainly increases with increasing characteristic length, aggregate stiffness, mean aggregate size and decreasing ITZ thickness. It may increase with increasing volume fraction of aggregate. It is also dependent upon aggregate shape,

- the width of a localized zone increases with increasing characteristic length and decreasing aggregate volume. It may increase if it propagates through weak grains. It is not affected by the aggregate size, aggregate shape, stochastic distribution, ITZ thickness and notch size. The width of a calculated localized zone above the notch changes from about $2 \times l_{c}^{m}(\rho=60 \%)$ up to $4 \times l_{c}^{m}(\rho=30 \%)$ at $l_{c}=1.5 \mathrm{~mm}$. If $l_{c}^{m}=5$ $\mathrm{mm}$, the width of a calculated localized zone above the notch changes from $2.8 \times l_{c}^{\mathrm{m}}$ $(\rho=60 \%)$ up to $3.5 \times l_{c}^{m}(\rho=30 \%)$,

- the calculated increment rate of the width of a localized zone is similar as in experiments,

- concrete softening is strongly influenced by the statistical distribution of aggregate, characteristic length, volume fraction of aggregate, aggregate shape, aggregate stiffness and ITZ thickness.

The mesoscopic modelling allows for a better understanding of the mechanism of strain localization. However, it cannot be still used for engineering problems due to a long computation time and too small knowledge on both properties of meso-phases in concrete and a stochastic distribution of aggregate which are of a major importance. A direct link between a characteristic length and material micro-structure remains still open. To realistically describe the entire fracture process in concrete, a combined continuous-discontinuous numerical approach has to be used [38], [39].

\section{Aknowledgements}

Research work has been carried out within the project: "Innovative ways and effective methods of safety improvement and durability of buildings and transport infrastructure in the sustainable development" financed by the European Union (POIG.01.01.02-10-106/09-01).

The numerical calculations were performed on supercomputers of the Academic Computer Centre in Gdansk TASK. 


\section{REFERENCES}

1. Z.P. BažAnt, J. Planas, Fracture and size effect in concrete and other quasi-brittle materials, CRC Press LLC, Boca Raton, 1998.

2. G. Lillu, J.G.M van Mier, $3 D$ lattice type fracture model for concrete, Engineering Fracture Mechanics, 70, 927-941, 2003.

3. A.U. Nielsen, P.J.M. Montiero, O.E. Gjorv, Estimation of the elastic moduli of lightweight aggregate, Cement and Concrete Research, 25, 276-280, 1995.

4. O. Sengul, C. TASDEmiR, M.A. TASDEmir, Influence of aggregate type on mechanical behaviour of normal- and high-strength concretes, ACI Master Journal, 99, 528-533, 2002.

5. J. Kozicki, J. Tejchman, Modelling of fracture processes in concrete using a novel latice model, Granular Matter, 10, 377-388, 2008.

6. H. He, Computational modeling of particle packing in concrete, PhD Thesis, Delft University of Technology, 2010.

7. S.M. Kim, R.K. Aвu AL-Rub, Meso-scale computational modelling of the plastic-damage response of cementitious composites, Cement and Concrete Research, 41, 339-358, 2011.

8. S. Shahbeyк, M. Hosseini, M. Yaghoobi, Mesoscale finite element prediction of concrete failure, Computational Materials Science, 50, 1973-1990, 2011.

9. I. Marzec, J. Bobiński, J. TeJchman, Simulations of crack spacing in reinforced concrete beams using elastic-plastic and damage with non-local softening, Computers and Concrete, 4, 377-403, 2007.

10. Ł. Skarżyński, J. Tejchman, Calculations of fracture process zones on meso-scale in notched concrete beams subjected to three-point bending, European Journal of Mechanics A/Solids, 29, 4, 746-760, 2010.

11. G. Pijauder-Cавот, Z.P. BažAnt, Non-local damage theory, ASCE Journal of Engineering Mechanics, 113, 1512-1533, 1987.

12. Z.P. BAŽANT, M. JIRASEK, Non-local integral formulations of plasticity and damage: survey of progress, Journal of Engineering Mechanics, 128, 1119-1149, 2002.

13. J. Bobińsкi, J. Tejchman, J. GóRsкi, Notched concrete beams under bending - calculations of size effects within stochastic elaso-plasticity with non-local softening, Archives of Mechanics, 61, 1-25, 2009.

14. Ł. Skarżyński, E. Syroka, J. Tejchman, Measurements and calculations of the width of the fracture process zones on the surface of notched concrete beams, Strain, 47, e319-e322, 2011.

15. I.M. Gitman, H. Askes, L.J. Sluys, Representative volume: Existence and size deterimantion, Engineering Fracture Mechanics, 74, 2518-2534, 2007.

16. C.B. Du, L.G. Sun, Numerical simulation of aggregate shapes of two dimensional concrete and its application, Journal of Aerospace Engineering, 20, 172-178, 2007.

17. H. He, Z. Guo, P. Stroeven, M. Stroeven, L.J. Sluys, Influence of Particle Packing on Elastic Properties of Conference, The First International Conference on Computational Technologies in Concrete Structures (CTCS'09), Jeju, Korea, May 24-27, 2009.

18. L.M. Katchanov, Introduction to continuum damage mechanics, Dordrecht: Martimus Nijhoff, 1986.

19. J.C. Sімо, J.W. Ju, Strain- and stress-based continuum damage models - I. Formulation. International Journal of Solids and Structures, 23, 821-840, 1987.

20. M. JiRASeK, S. Marfia, Non-local damage model based on displacement averaging, International Journal for Numerical Methods in Engineering, 63, 77-102, 2005.

21. R.H.J. Peerlings, R. De Borst, W.A.M. Brekelmans, M.G.D. Geers, Gradient enhanced damage modelling of concrete fracture, Mechanics of Cohesion - Frictional Materials, 3, 323-342, 1998.

22. J. Bobiński, J. Tejchman, Continuous and discontinuous modeling of cracks in concrete elements, Modelling of Concrete Structures (eds. N. Bicanic, R. de Borst, H. Mang, G. Meschke), Taylor and Francis Group, London, 263-270, 2010. 
23. E. Syroka, J. Bobiński, J. Tejchman, FE analysis of reinforced concrete corbels with enhanced continuum models, Finite Element Methods in Analysis and Design, 47, 9, 1066-1078, 2011.

24. A. Simone, L.J. Stuys, The use of displacement discontinuities in a rate - dependent medium, Computational Methods in Applied Mechanics Engineering, 193, 3015-3033, 2004.

25. J. Boвí́sкi, J. Tелснмаn, Numerical simulations of localization of deformation in quasi-brittle materials with non-local softening plasticity, Computers and Concrete, 4, 433-455, 2004.

26. А. Wosatкo, J. Pamin, A. Winnicki, Gradient damage in simulations of behaviour of RC bars and beams under static and impact loading, Archives of Civil Engineering, 52, 2, 455-477, 2006.

27. C. Le Bellěgo, J.F. Dube, G. Pijaudier-Cabot, B. Gerard, Calibration of nonlocal damage model from size effect tests, European Journal of Mechanics A/Solids, 22, 33-46, 2003.

28. S. Eckardt, C. KönKe, Simulation of damage in concrete structures using multi-scale models, Computational Modelling of Concrete Structures, EURO-C (G. Meschke, R. de Borst, H. Mang and N. Bicanic, editors), Taylor and Francis, 77-89, 2006.

29. J.G.M. van Mier, E. Schlangen, A. Vervuurt, Lattice type fracture models for concrete, Continuum models for material microstructure (editor H.B. Mühlhaus), John Wiley \& Sons, 341-377, 1995.

30. I.M. Gitman, H. Askes, L.J. Sluys, Coupled-volume multi-scale modelling of quasi-brittle material, European Journal of Mechanics A/Solids, 27, 302-327, 2008.

31. Z.P. BažANT, B.Н. Он, Crack band theory for fracture of concrete. Material Structures, RILEM 16, 155-177, 1983.

32. H. Мinashi, N. Nomura, Correlation between characteristics of fracture process zone and tension softening properties of concrete, Nuclear Engineering and Desing, 165, 359-376, 1996.

33. E. Syroka, J. Tejchman, Experimental investigations of size effect in reinforced concrete beams without shear reinforcement, Internal Report, Gdańsk University of Technology, 2011.

34. K.L. Scrivener, A.K. Crumbie, P. Laugesen, The interfacial transition zone (ITZ) between cement paste and aggregate in concrete, Interface Science, 411-421, Springer Netherlands, http://dx.doi.org/ 10.1023/B:INTS.0000042339.92990.4c, 2004.

35. P. Mondal, S.P. Shah, L.D. Marks, Nanomechanical properties of interfacial transition zone in concrete, Nanotechnology in Construction 3, Springer, 315-320, 2009.

36. M. Ortiz, A. Pandolfi, Finite-deformation irreversible cohesive elements for three-dimensional crack-propagation analysis, International Journal for Numerical Methods in Engineering, 44, 1267-1282, 1999.

37. T. Belytschko, N. Moes, S. Usui, C. Parimi, Arbitrary discontinuities in finite elements, International Journal for Numerical Methods in Engineering, 50, 4 , 993-1013, 2001.

38. P. Moonen, J. Carmeliet, L.J. Sluys, A continuous-discontinuous approach to simulate fracture processes, Philosophical Magazine, 88, 3281-3298, 2008.

39. J. Tejchman, J. Bobińsкi, Continuous and discontinuous modeling of fracture in concrete using FEM, Springer, Berlin-Heidelberg (eds. W. Wu and R. I. Borja), 2012.

Remarks on the paper should be sent to the Editorial Office no later than December 31, 2012
Received April 22, 2012 revised version August 25, 2012 